\title{
Tropische Falter im neuen Blüten- und Schmetterlingshaus des Palmengartens
}

\author{
Hilke Steinecke, Marco Schmidt, Alexander Becker, \\ Justine Hillen brand \& Beate Vaupel
}

\begin{abstract}
The newly opened Flower and Butterfly House is a major attraction in the Palmengarten. Depending on the season, several dozen different species of butterflies can be observed here. The butterflies are ordered as chrysalises in Costa Rica from sustainable breeding. Depending on their food preference, the butterflies can be observed visiting real nectar plants, artificial feeding places or fruit chains. For some species, caterpillar food plants are also offered. The most important and regularly shown species are briefly presented.
\end{abstract}

\section{Zusammenfassung}

Das neu eröffnete Blüten- und Schmetterlingshaus ist eine große Attraktion im Palmengarten. Je nach Saison können hier mehrere Dutzend verschiedene Schmetterlingsarten beobachtet werden. Sie werden in Form von Puppen in Costa Rica aus nachhaltiger Zucht bestellt. Die Falter können je nach Nahrungsvorliebe an echten Nektarpflanzen, künstlichen Futterstellen oder Obstketten bei der Nahrungsaufnahme beobachtet werden. Für einige Arten werden auch Raupenfutterpflanzen angeboten. Die wichtigsten und regelmäßig gezeigten Arten werden kurz vorgestellt.

\section{Einleitung}

Bereits vor vielen Jahren hatte Matthias Jenny, Palmengarten-Direktor bis Anfang 2018, die Vision eines Blüten- und Schmetterlingshauses im Palmengarten. Planung, Finanzierung und Umsetzung zogen sich über Jahre hinweg. Schließlich aber konnten das in die Jahre gekommene Blütenhaus und die alten Anzuchthäuser der Nordhalle in der Gärtnerei abgerissen werden. Unter der neuen Gartenleitung von Katja Heubach wurden dann die Neubauten errichtet und ein pädagogisches Konzept erarbeitet. Die Haupt-Bauaktivitäten erfolgten im Jahr 2019. Das Blüten- und Schmetterlingshaus ist in einen Kalt- und Warmhausbereich unterteilt. Das Warmhaus ist tropisch bepflanzt und beherbergt zeitweise die Schmetterlinge. Im Kalthaus wird eine Dauerausstellung zur Blütenund Bestäuberökologie gezeigt.

Im Winter 2020/21 wurde ein erster besucherfreier Testlauf mit Schmetterlingen durchgeführt. Die geplante offizielle Eröffnung passend zum Festakt „150 Jahre Palmengarten“ im März 2021 musste coronabedingt auf den Sommer verschoben werden.

Die Schmetterlinge stammen aus Costa Rica von „Costa Rica Entomological Supply (CRES)”. Die Zuchtfarmen arbeiten ökologisch und nach- haltig. Etwa hundert Familien pflanzen auf ihren Farmen Nektarpflanzen für die Falter und Futterpflanzen für Raupen verschiedener dort heimischer Schmetterlingsarten an. Wild lebende Schmetterlinge legen ihre Eier auch auf diesen Pflanzen ab. So können sich die Raupen gut vor Fressfeinden geschützt bis zur Verpuppung entwickeln. Um auch die Schmetterlingsvielfalt in ihrem Umfeld zu erhalten, schützen die Farmer die umliegende Natur einschließlich des Regenwaldes. Diese Zucht von Schmetterlingen sichert den Familien ein geregeltes Einkommen. Züchter und Vertrieb erfüllen die Bestimmungen des internationalen Artenschutzabkommens (CITES).

Die frischen Schmetterlingspuppen werden zentral gesammelt und weltweit an entsprechende Schmetterlingshäuser nach genauem Zeitplan geschickt, damit die Schmetterlinge nicht schon zu früh während des Transportes schlüpfen. Alle für Deutschland vorgesehenen Puppen kommen in Frankfurt an, wo auch Zoll- und Artenschutzpapiere geprüft werden. Vom Flughafen ist es dann nicht mehr weit in den Palmengarten.

Im Palmengarten ist dienstags Puppentag. Gut isoliert und vor niedrigen Temperaturen geschützt kommt alle zwei Wochen ein Päckchen Puppen verschiedenster Arten an. Umgehend werden die 



Abb. 1: Schmetterlingsfarm in Costa Rica, Zucht der Raupen, Sammeln, Kontrollieren, Sortieren und Verpacken der Puppen. (Fotos: G. BLAESE) 


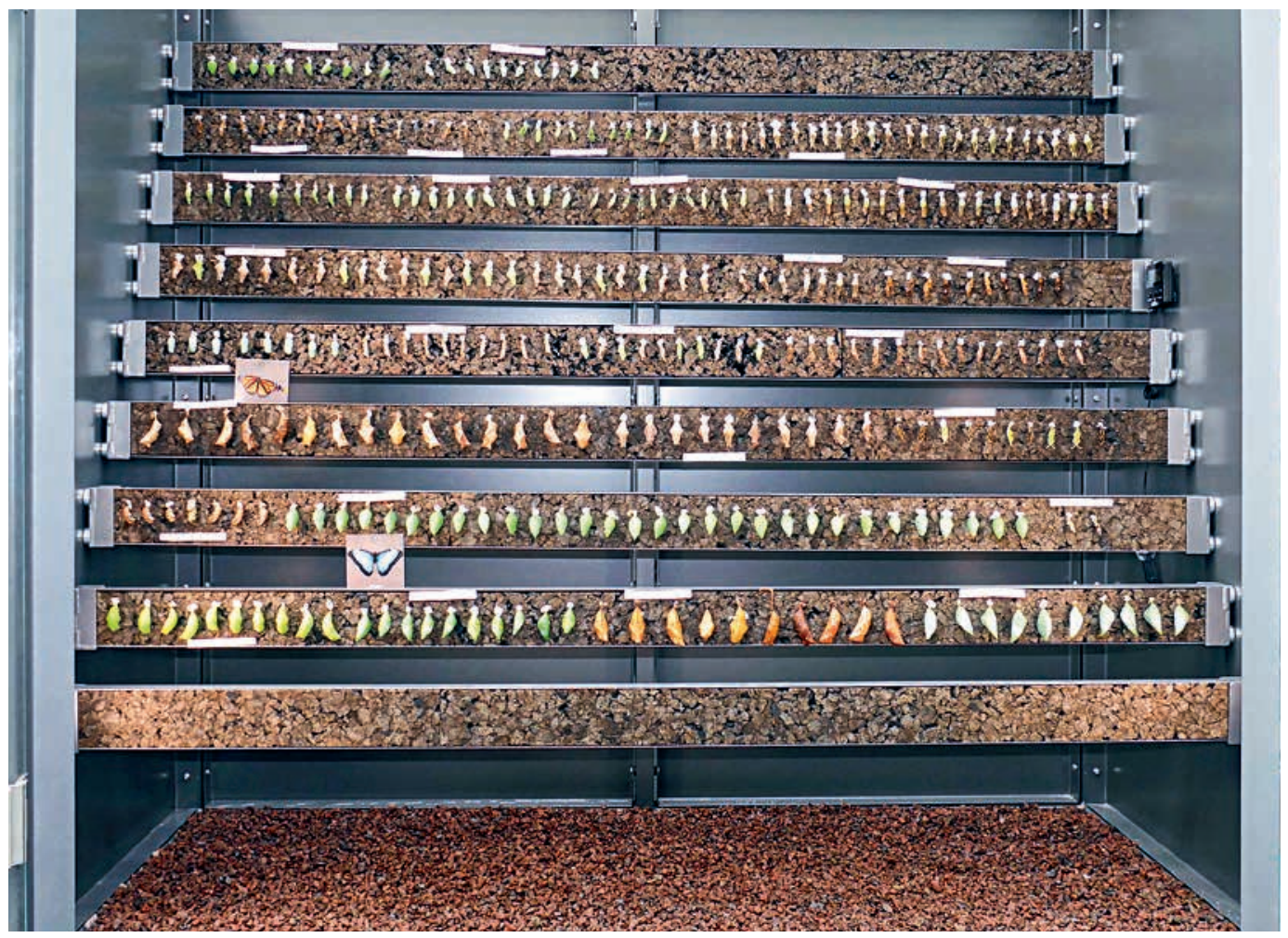

Abb. 2: Das frisch bestückte „Puppenhaus“. (Foto: H. Steinecke)

Puppen in einem gläsernen „Puppenhaus“ im Warmhaus an Korkleisten aufgehängt. Wichtig für die Entwicklung der Puppen ist eine hohe Luftfeuchtigkeit von etwa $80 \%$. Diese wird gewährleistet, indem der mit Granulat ausgelegte Boden regelmäßig mit Wasser befeuchtet wird, die Kontrolle der Luftfeuchtigkeit erfolgt mittels Hygrometer. Im Glashaus ist von Zeit zu Zeit auch eine Sprühnebelanlage in Betrieb. Die Puppen sind ganz unterschiedlich gestaltet. Einige imitieren trockenes Laub, manche wirken wie kleine grüne Tönnchen. Andere sind goldglänzend oder metallisch getupft und erinnern an filigrane Schmuckstücke und wenige sind in einem Kokon eingesponnen.

Artspezifisch schlüpfen aus den Puppen nach einigen Tagen die Schmetterlinge, die dann im Blüten- und Schmetterlingshaus frei herumfliegen dürfen. Die Lebensdauer der meisten Schmetterlinge ist recht kurz und reicht von wenigen Tagen bis zu ein paar Wochen. Längere Zeit haben die

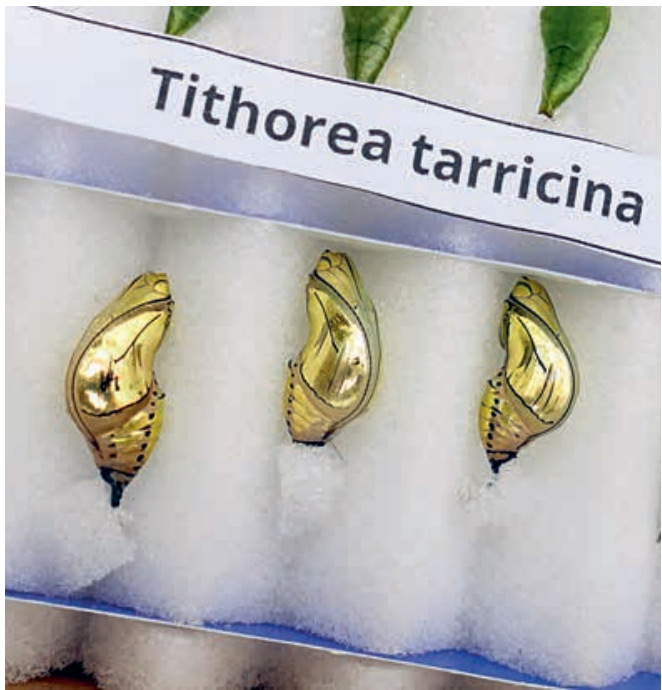

Abb. 3: Fast wie Schmuck in einem Schmuckkästchen wirken die Puppen in der Transportschachtel. Bereits in Costa Rica werden sie an der Spitze mit einem Stück Schaumstoff oder Schaumgummi versehen, an dem man sie mit einer Stecknadel an den Leisten im „Puppenhaus“ befestigen kann. (Foto: H. STeinecke) 


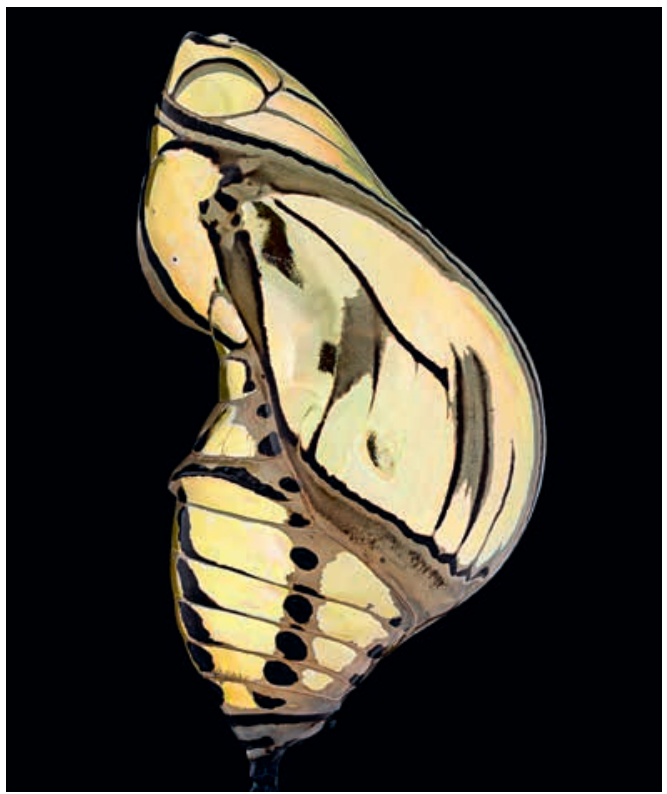

Abb. 4: Eine Puppe von Tithorea tarracina (cream-spotted tigerwing) im Detail: Ein Kunstwerk der Natur.

(Foto: J. MARKwirth)
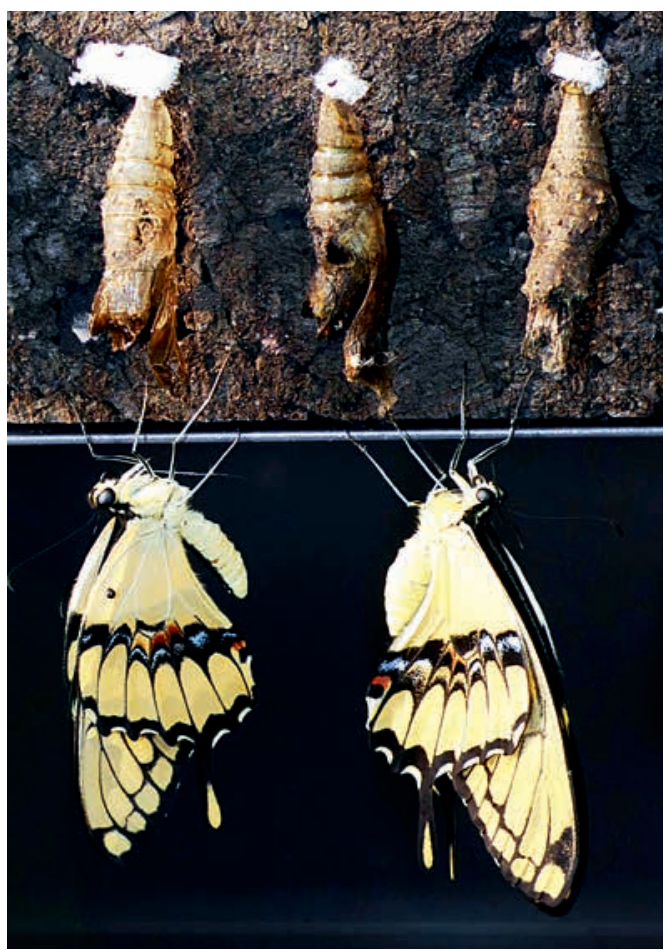

Abb. 6: Zwei Königs-Schwalbenschwänze (Papilio thoas) sind frisch geschlüpft und hängen noch von ihrer leeren Puppenhülle. (Foto: H. STEINECKe)

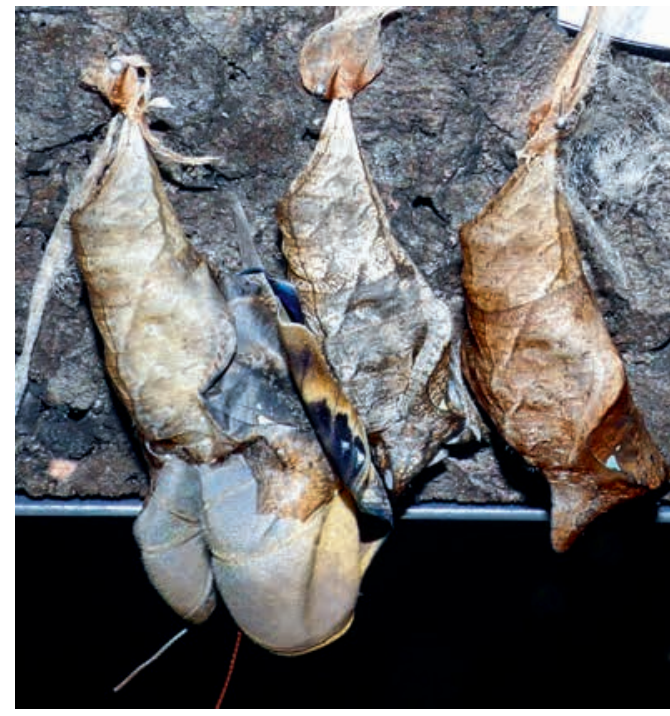

Abb. 5: Wenn die Puppenhülle platzt, kann sich der fertige Schmetterling (hier ein Blauer Bananenfalter, Caligo atreus) schnell befreien, deutlich länger dauert es, bis die Flügel voll entfaltet sind. (Foto: H. STEINECKe)

Falter im Raupen- und Puppenstadium verbracht. In Abhängigkeit von der Jahreszeit finden die Tiere im Gewächshaus echte Nektarpflanzen vor wie z. B. das Wandelröschen (Lantana camara) oder das Eisenkrautgewächs Stachytarpheta mutabilis. Der Schlitzblatt-Hibiskus (Hibiscus schizopetalus) ist zwar eine typische Vogelblume, die Blüten werden hier aber auch gern von Nektar trinkenden Schmetterlingen aufgesucht. Zudem gibt es farbige Futterstationen mit Schwämmen, die mit einer Zucker-Honiglösung getränkt sind. Manche Schmetterlinge bevorzugen reifes bis gärendes Obst. Für sie stehen Ketten mit aufgefädelten Orangen- und Bananenstücken zur Verfügung.

Für manche Arten finden sich auch Futterpflanzen für ihre Raupen. Alle Pflanzen hierfür kommen aus der Anzucht der Gärtnerei und werden komplett ohne Pestizide herangezogen, denn schon kleinste Spuren von giftigen Pflanzenschutzmitteln würden Falter und Raupen sterben lassen.

\section{Die großen Auffälligen}

Ein Muss für jedes Schmetterlingshaus ist der Himmels- oder Morphofalter (Morpho 
peleides). Er ist von Mexiko bis ins nördliche Südamerika noch weit verbreitet. Wenn der Himmelsfalter mit seinen breiten Flügeln (Spannweite bis $12 \mathrm{~cm}$ ) durch die Lüfte gaukelt, schimmern seine Flügeloberseiten stahlblau. Diese außergewöhnliche Färbung geht nicht auf Pigmente zurück, sondern auf Interferenzeffekte des Lichtes auf den dachziegelartig angeordneten Flügelschuppen. Auf der Unterseite der Vorder- sowie Hinterflügel befinden sich große gelbrandige Augenflecken. Sie sollen Fressfeinde abschrecken, weil diese darin fälschlicherweise Augen von beispielsweise Schlangen vermuten. Meist sitzt der Himmelsfalter mit geschlossenen Flügeln still herum. Er stützt sich dabei nur auf vier Beinen $\mathrm{ab}$, denn das vorderste Beinpaar ist, wie bei allen Edelfaltern (Nymphalidae), zu Putzpfoten reduziert. Himmelsfalter ernähren sich von reifem bis gärendem Obst.

Ebenfalls zu den Edelfaltern gehören die mit den Himmelsfaltern eng verwandten Bananenfalter (Caligo). Mit über 20 Arten sind sie von Mexiko bis nach Südamerika verbreitet. Sie zählen mit Flügelspannweiten bis $16 \mathrm{~cm}$ zu den größten Tagfaltern überhaupt. Die Falter sind dämmerungsaktiv und sitzen tagsüber meist ruhig und etwas versteckt mit zusammengefalteten Flügeln oder saugen an Obst. Ihre bräunliche Grundfarbe der Flügel imitiert Rinde und tarnt sie gut. Zwei große beige umrandete Augenflecken haben für Fressfeinde eine abschreckende Wirkung. Die Spitzen der Vorderflügel wirken wie ein Schlangenkopf mit zwei Augen und breitem Maul. Bewährt für Schmetterlingshäuser haben sich die beiden Arten Caligo memnon und Blauer Bananenfalter (Caligo atreus). Ersterer ist unauffällig mit graubraunen bis etwas blau schimmernden Flügeloberseiten. Bei $C$. atreus ist das Blau kräftiger, außerdem tragen die Hinterflügel jeweils ein breites oranges Band. Bananenfalter legen ihre Eier auf Blättern von Bananenstauden und den verwandten Helikonien, Indischem Blumenrohr oder Pfeilwurzgewächsen ab. Sie fressen aber auch Blätter von Bromelien. Die jungen nachtaktiven zweischwänzigen Raupen sind grün und ruhen tagsüber gruppenweise auf den Mittelrippen der Blätter, wo sie äußerst gut

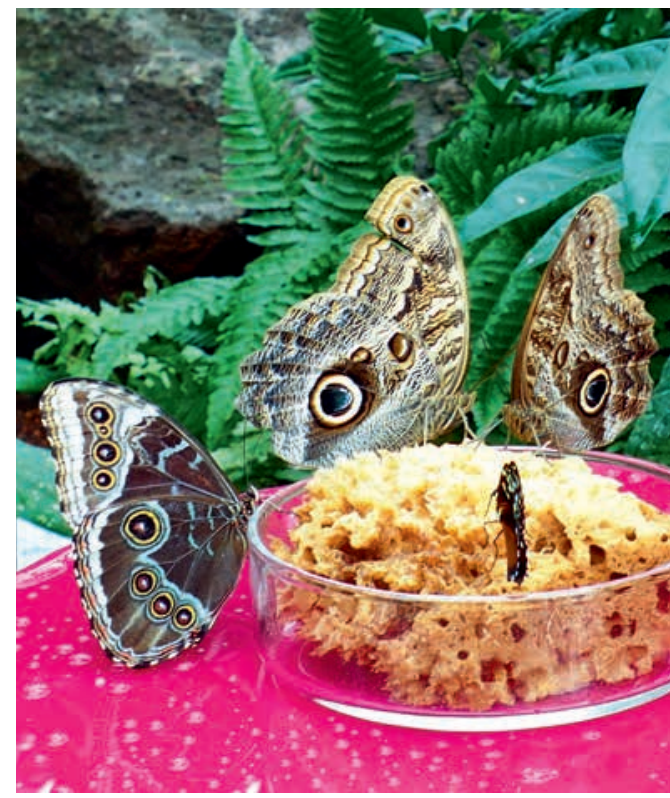

Abb. 7: Die Futterstation lockt verschiedene Arten an. Links ein Himmelsfalter (Morpho peleides), rechts zwei Bananenfalter (Caligo memnon). (Foto: H. STEINECKe)

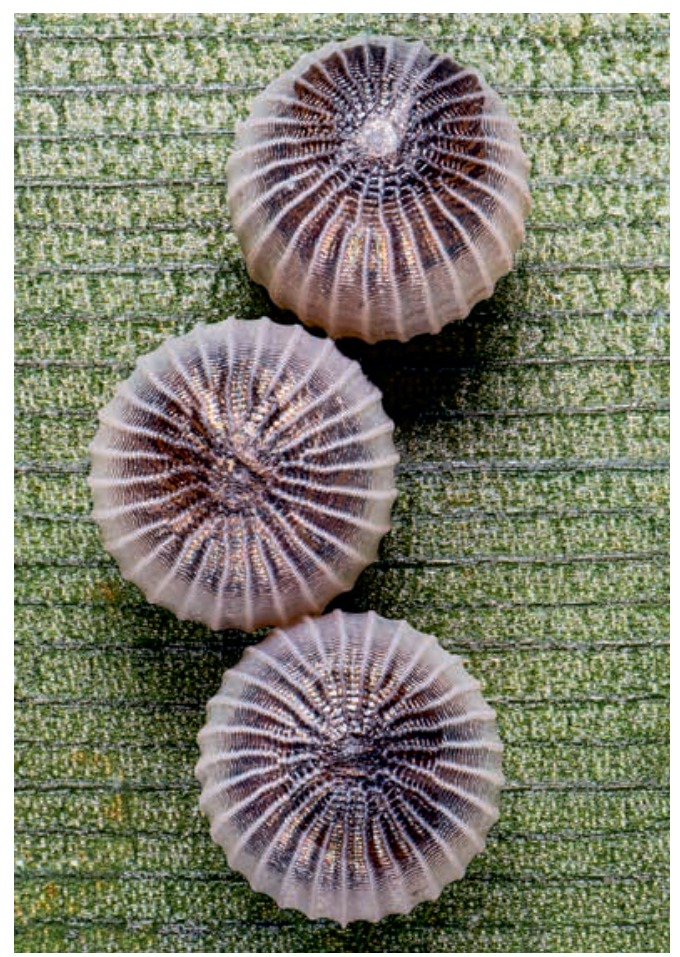

Abb. 8: Eier des Bananenfalters (Caligo memnon) auf einem Bananenblatt im Blüten- und Schmetterlingshaus, einen Tag vor dem Schlüpfen der Raupen. (Foto: J. Markwirth) 

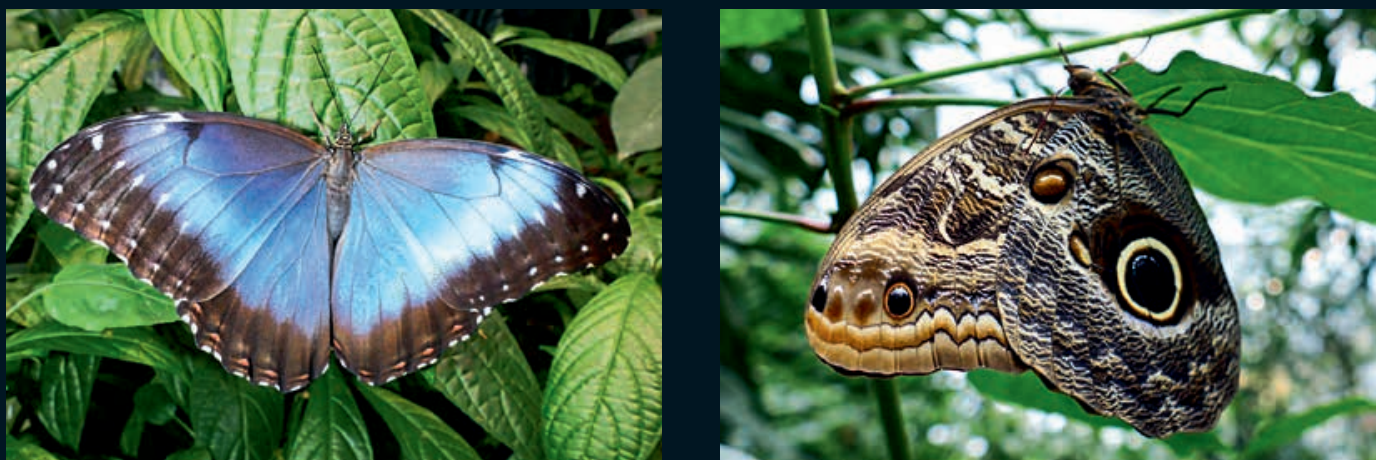

$\mathrm{b}$
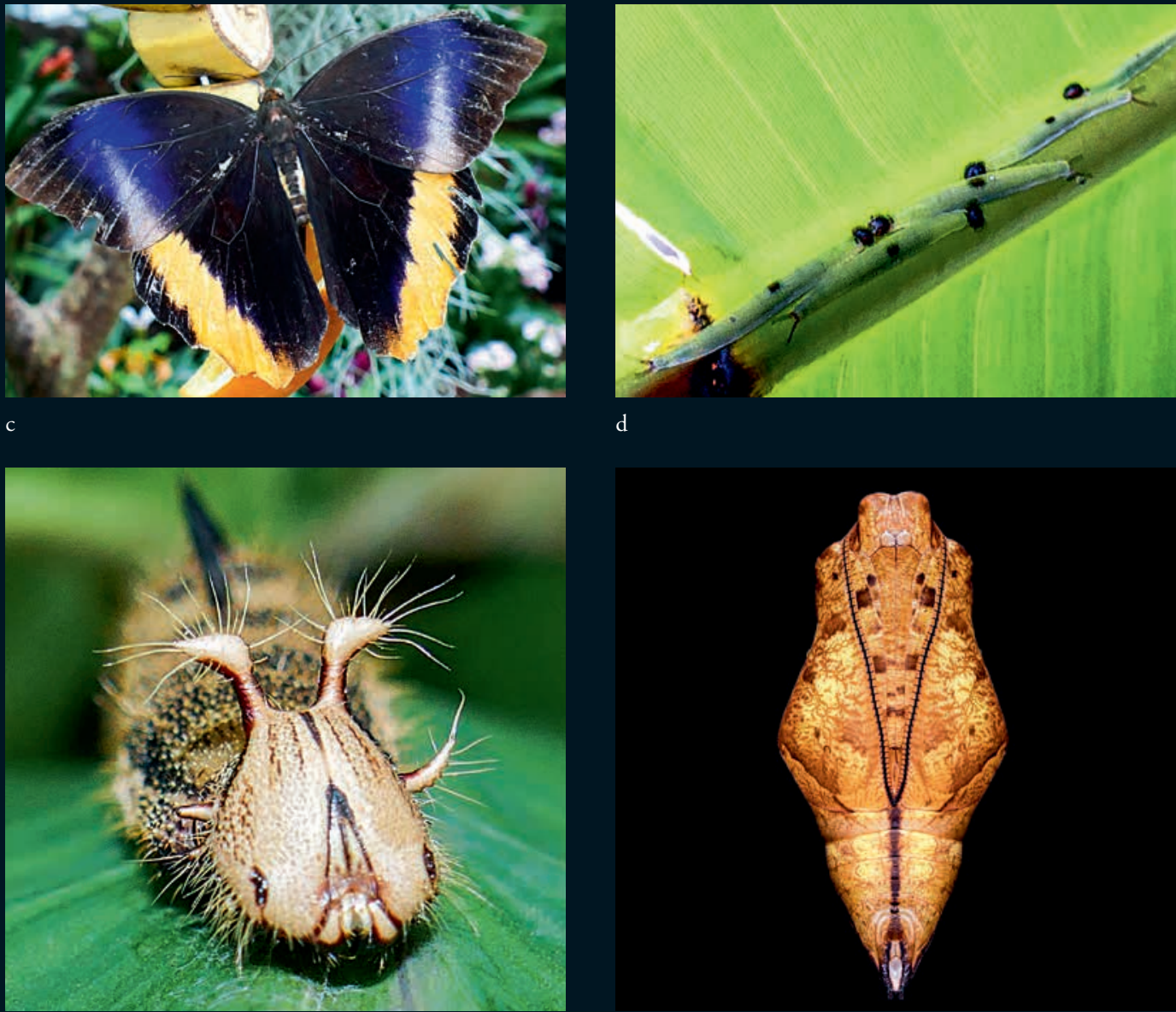

Abb. 9: Himmels- und Bananenfalter in verschiedenen Entwicklungsstadien. a: Himmelsfalter (Morpho peleides) mit seinen stahlblauen Flügeloberseiten; b: Bananenfalter (Caligo memnon) mit Augenflecken und Vorderflügelspitze, die an einen Schlangenkopf mit zwei Augen, zwei Nasenlöchern und Maul erinnert; c: Ein Blauer Bananenfalter (Caligo atreus) saugt an einer Fruchtkette; d: Junge Caligo-Raupen halten sich tagsüber gruppenweise im Bereich der Mittelrippen von Bananenblättern auf und fressen nachts; e: Ältere braune Caligo-Raupe mit großem Kopf; f: Sturzpuppe von Caligo atreus. (Fotos: J. MarkwirTh, Puppe unten rechts; alle anderen: H. STEINECKE). 


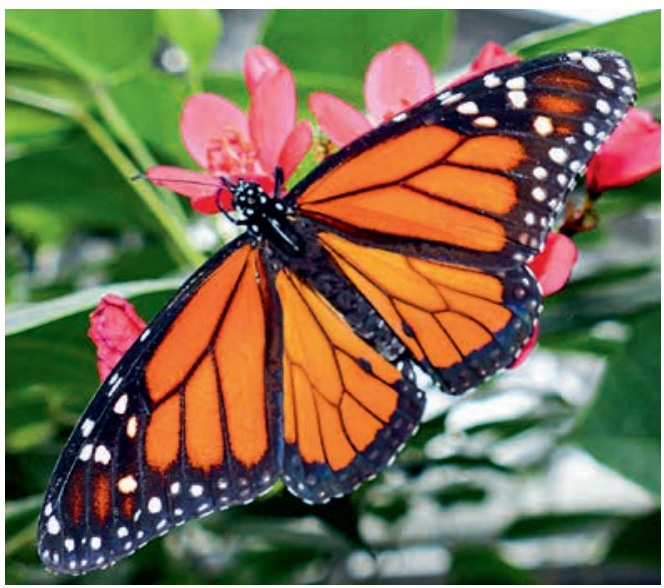

Abb. 10: Monarch (Danaus plexippus). (Foto: H. Steinecke)

getarnt sind. Ältere Raupen sind braun und etwas weich behaart. Ihr heller, dunkel gestreifter Kopf trägt nicht stechende, dornenähnliche Anhängsel. Die Raupen werden größer als ein Zeigefinger, entwickeln dementsprechend einen immensen Appetit. In Bananenplantagen gelten sie deshalb als Schädlinge. Die kräftigen Puppen sehen wie welke Blätter aus.

\section{Noch mehr Edelfalter}

Ein ziemlich bekannter Wanderfalter ist der Monarch (Danaus plexippus). Mit seiner orange-schwarz-weißen Flügelzeichnung ist er ein besonders auffälliger und auch gut zu erkennender Tagfalter. Seine Warnfarbe weist auf die Giftigkeit hin. Denn die Raupen leben auf den giftigen Seidenpflanzen (Asclepias). Die Tiere sind aber selbst gegen das Pflanzengift immun und speichern die auch für den Menschen giftigen Glykoside sogar im ausgewachsenen Falter. Der Monarch hat ein weites Verbreitungsgebiet von Nord- bis Südamerika. Mittlerweile ist er in vielen wärmeren Gebieten eingebürgert, so auch auf den Azoren, auf Madeira und den Kanaren. Da Seidenpflanzen auf diesen Inseln beliebte Zierpflanzen in Hotelgärten und Parks sind, können Monarchfalter dort häufig beobachtet werden. Als Wanderfalter kann der Monarch über $3000 \mathrm{~km}$ zurücklegen. Abermillionen Tiere überwintern in der mexikanischen Sierra Nevada. Allerdings sind die Bestände seit etwa 10 Jahren deutlich rückläufig.

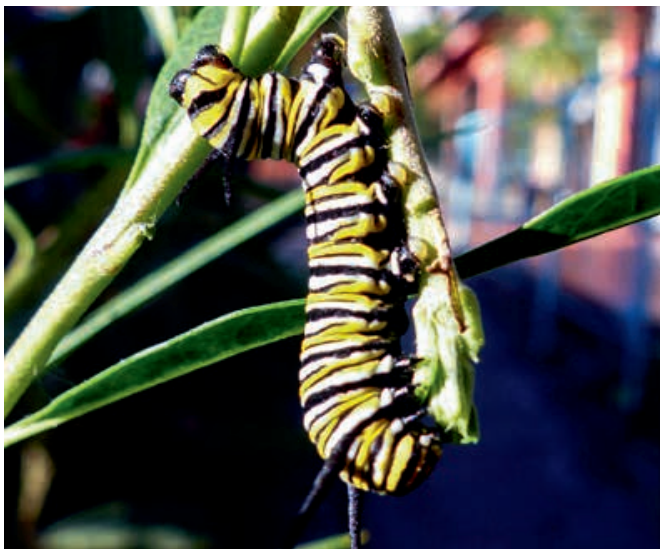

Abb. 11: Die markante Raupe des Monarchfalters in einem Hotelgarten auf Madeira. (Foto: H. STEINECKe)

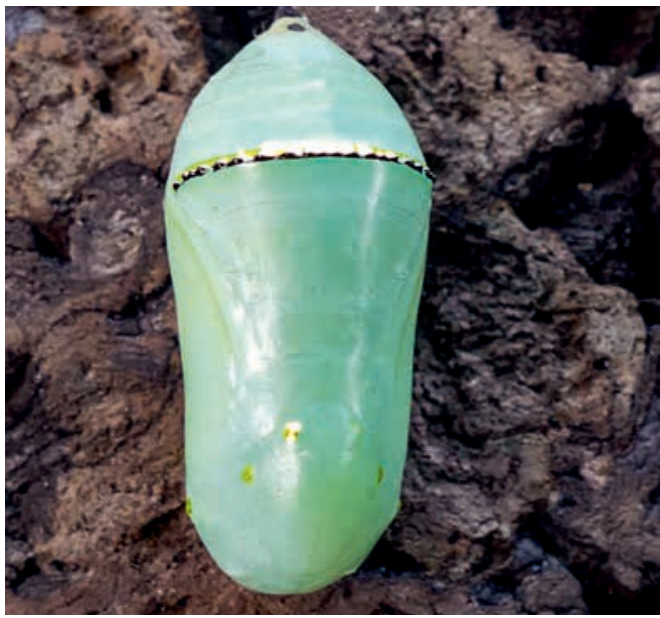

Abb. 12a: Wie aus Jade sieht die Sturzpuppe des Monarchfalters aus. (Foto: H. STEINECKE)

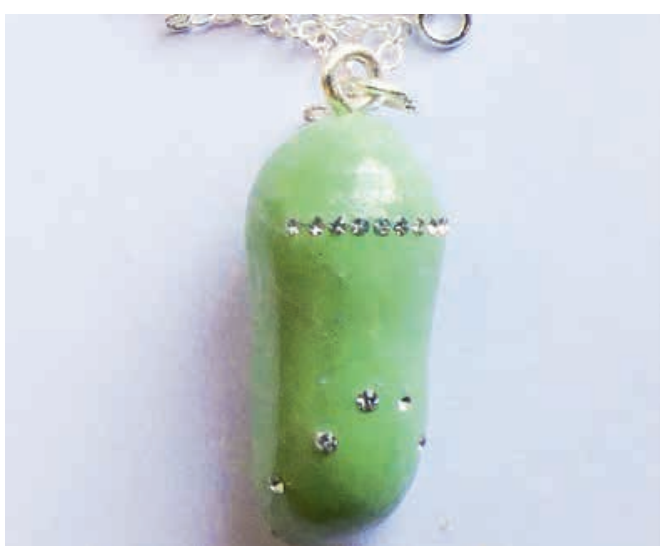

Abb. 12b: Ein in Neuseeland gefertigtes Schmuckstück in Form einer Monarch-Puppe aus Keramik. (Foto: H. Steinecke) 

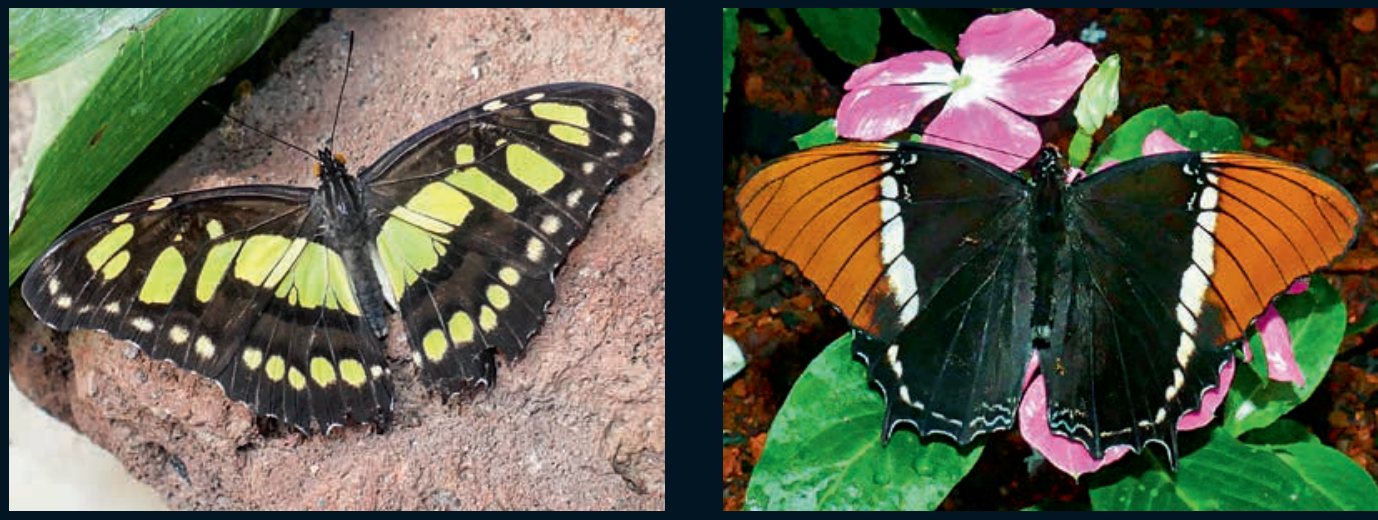

b
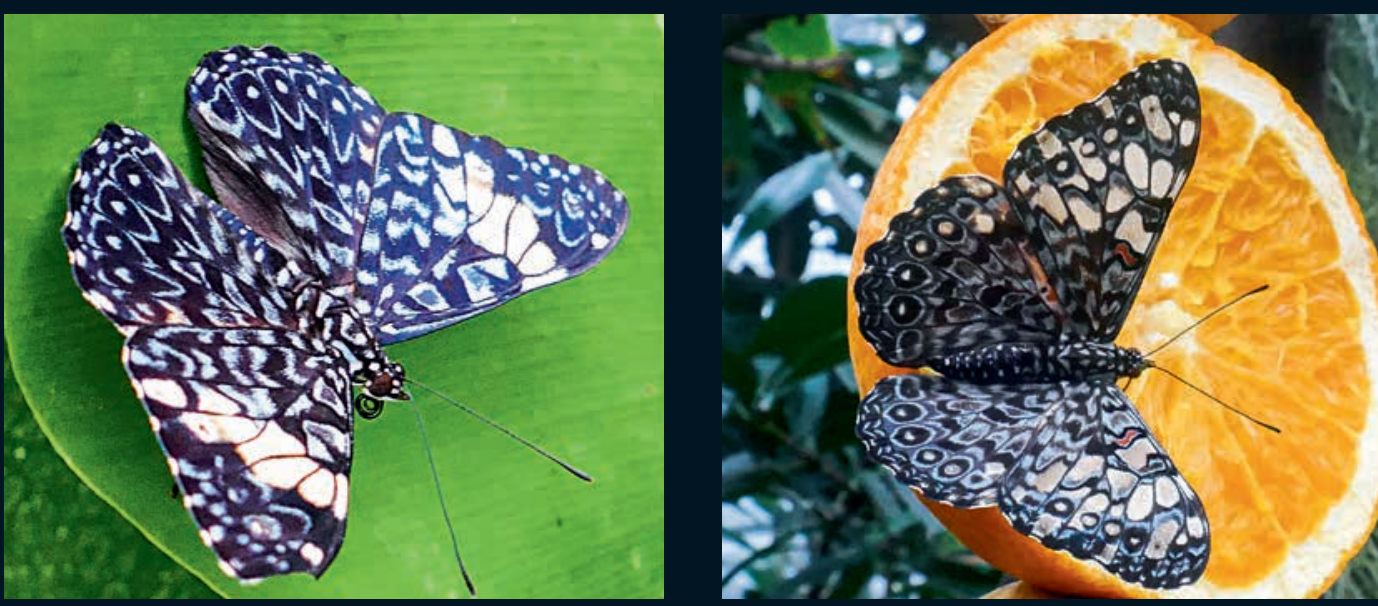

d
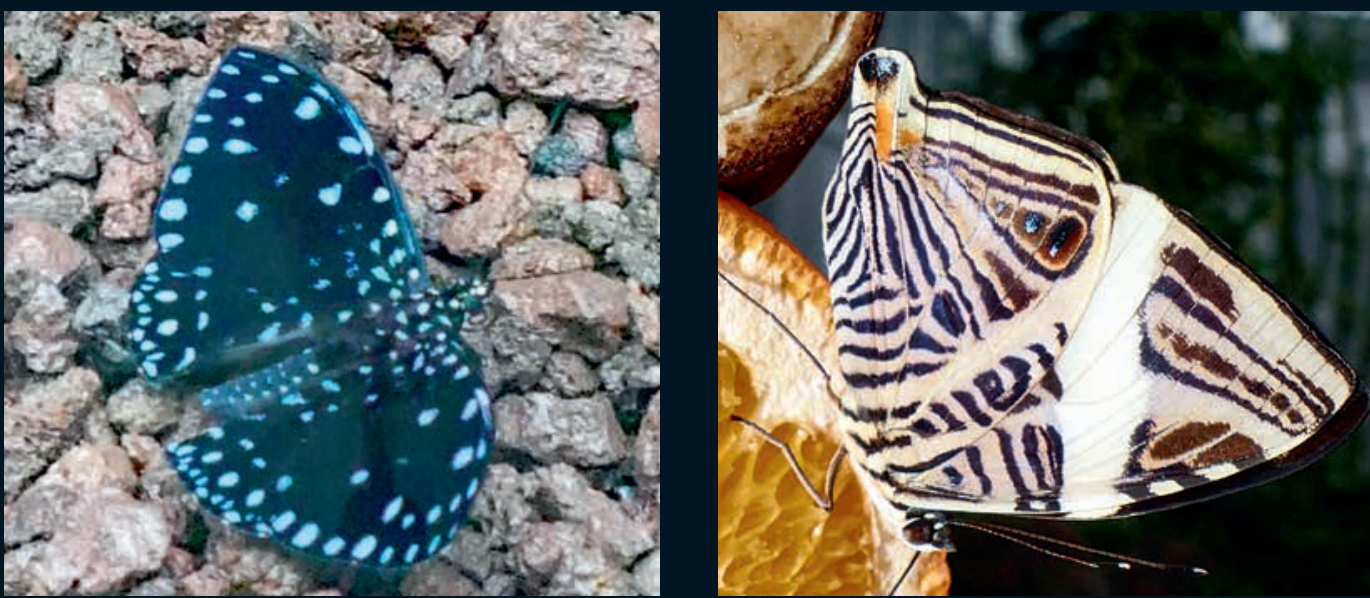

f

Abb. 13: Verschiedene Edelfalter. a: Malachitfalter (Siproeta stelenes); b: Schokoladenfalter (Siproeta epaphus); c: Mosaikfalter (Hamadryas amphinome); d: Mosaikfalter (Hamadryas feronia); e: Mosaikfalter (Hamadryas laodamia); f: Zebra-Mosaikfalter (Colobura dirce). (Fotos: H. STEINECKe) 


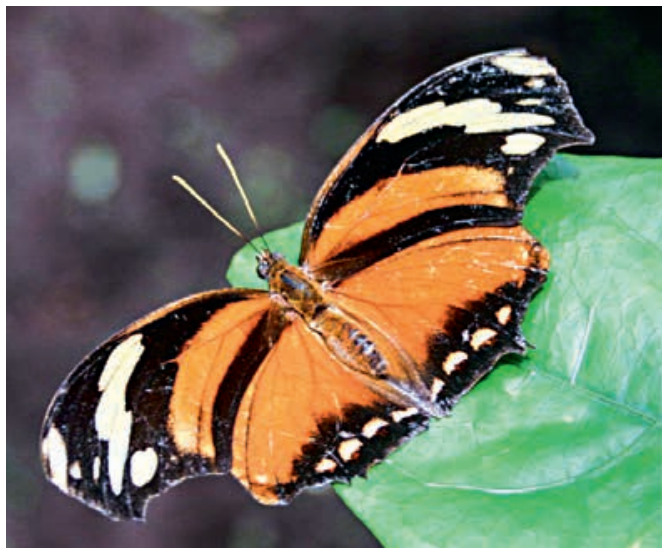

Abb. 14: Konsul Fabius, engl. „tiger leafwing“ (Consul fabius) imitiert Passionsblumenfalter. (Foto: G. BlaEsE)

Die glatten Raupen zeigen ringförmige weiße, gelbe und schwarze Bänder. Die Puppen, die natürlich auch in unserem „Puppenhaus“ zu bewundern sind, sind jadefarben mit goldenen Tupfen. Raupen und Puppen sind so attraktiv und vor allem in Amerika sehr populär, dass sie dort als Schmuckkettenanhänger nachgebildet werden.

Besonders attraktive Edelfalter sind in unserem Haus außerdem Malachit- sowie Schokoladenfalter (Siproeta stelenes und S. epaphus), deren Flügel eine malachitgrüne bzw. orange-braune Zeichnung tragen. Beide sind in Mittel- und Südamerika häufige Arten. Neben Nektar dienen auch reifes Obst, Dung und Aas als Nahrung. Im Regenwald lassen sie sich an feuchten Stellen wie Bachufern oder Pfützen nieder, um im Wasser gelöste Mineralstoffe aufzunehmen.

Auf Tarn- und Warnfärbung setzen Mosaikfalter (Hamadryas amphinome, H. feronia, H. laodamia). Die beiden erstgenannten Arten sind oberseits graublau marmoriert und dadurch getarnt. Hamaedryas laodamia schimmert bläulich mit vielen tiefblauen Punkten. Diese Warnfarbe schreckt Fressfeinde ab, denn die Raupen leben auf einem giften Wolfsmilchgewächs (Dalechampia triphylla), wodurch die Raupen und auch später die Schmetterlinge für Vögel ungenießbar werden. Hamadryas-Arten werden im englischen auch „cracker" genannt. Denn die Männchen geben beim

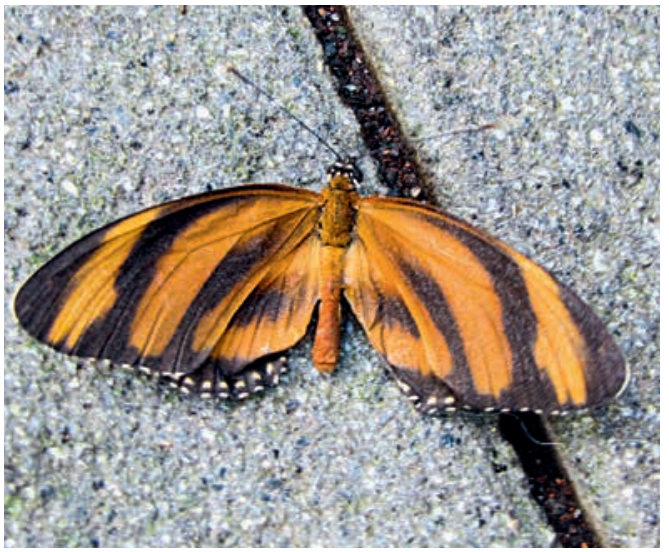

Abb. 15: Ähnlich wirkt der Orange Tiger (Dryadula phaetu$s a)$, ein Passionsblumenfalter. (Foto: H. Steinecke)

Fliegen knackende Geräusche von sich, die zur Anlockung von Weibchen, aber auch zur Vertreibung von konkurrierenden Männchen und Fressfeinden eingesetzt werden. Die Schmetterlinge nehmen keinen Nektar auf, sondern bevorzugen den Saft von Früchten.

\section{Der Zebra-Mosaikfalter (Colobura dirce)} ist oberseits dunkelbraun bis schwarz gefärbt mit einem weißlichen Querband auf den Vorderflügeln. Auf der Unterseite zeigt er ein auffällig schwarz-weißes Zebramuster. Die Falter sind meist sitzend in Ruhestellung zu sehen. Das Zebramuster löst, wie auch bei den Zebras, die Körperform auf, so dass sie von Tieren, die sie fressen würden, leicht übersehen werden. Anderseits lässt sich im leicht geschwänzten Hinterflügel auch ein „falscher Kopf“ erkennen, der Feinde über Körperausrichtung, Lage empfindlicher Organe und Fluchtrichtung täuscht. Der Zebra-Mosaikfalter saugt, wie auch die zuvor beschriebenen Mosaikfalter, an reifem Obst.

Passionsblumenfalter (Heliconiinae) sind eine Unterfamilie der Edelfalter, viele gehören der Gattung Heliconius an. Die mittelgroßen Falter sind vom südlichen Nordamerika über Mittel- bis nach Südamerika weit verbreitet und tragen einprägsame Volksnamen wie Postbote, Oranger Tiger, Zebra-, Julia-, Doris- oder Sarafalter. Sie haben relativ schmale Vorderflügel und Spannweiten bis etwa $9 \mathrm{~cm}$. Sie sind meist 

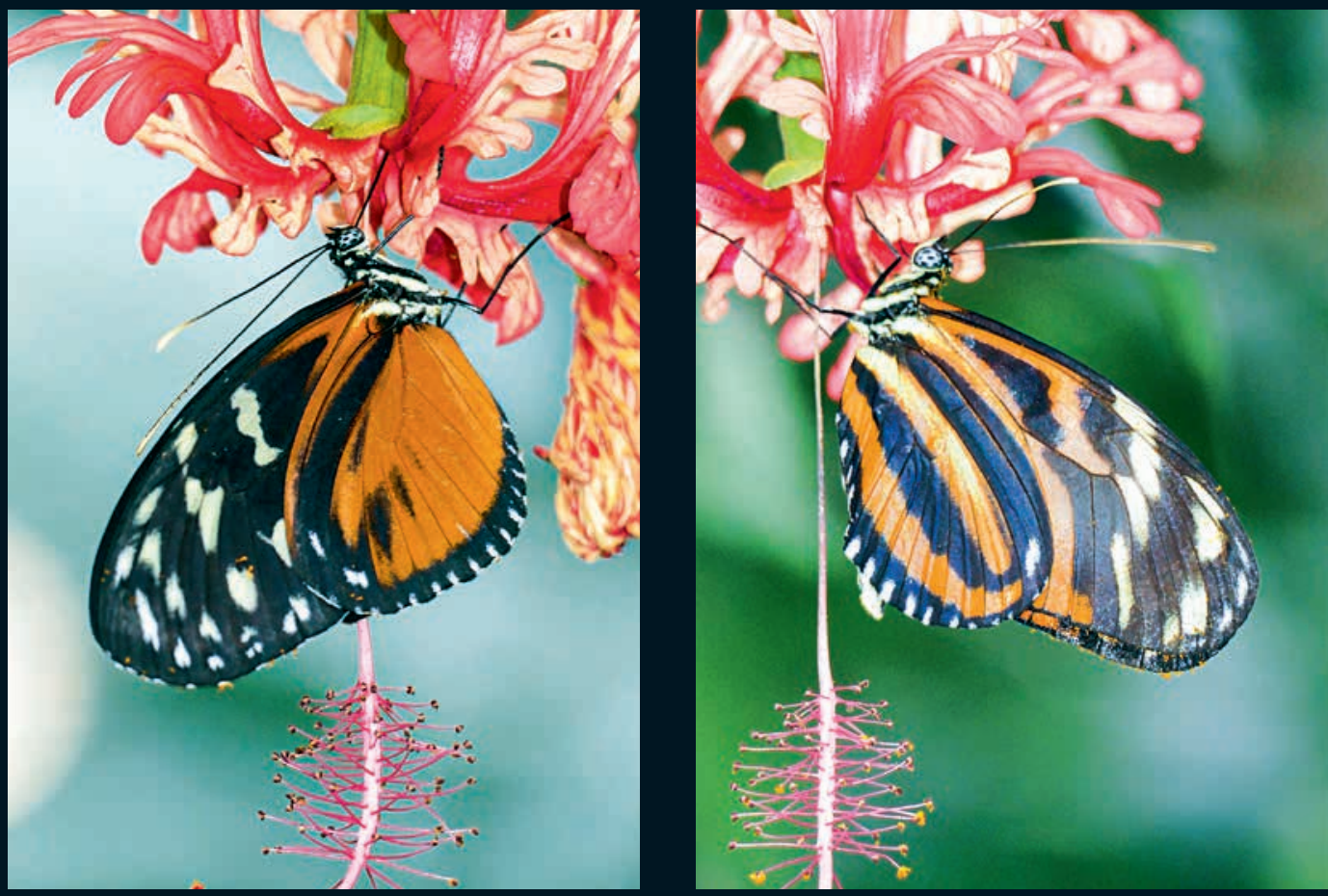

a

b
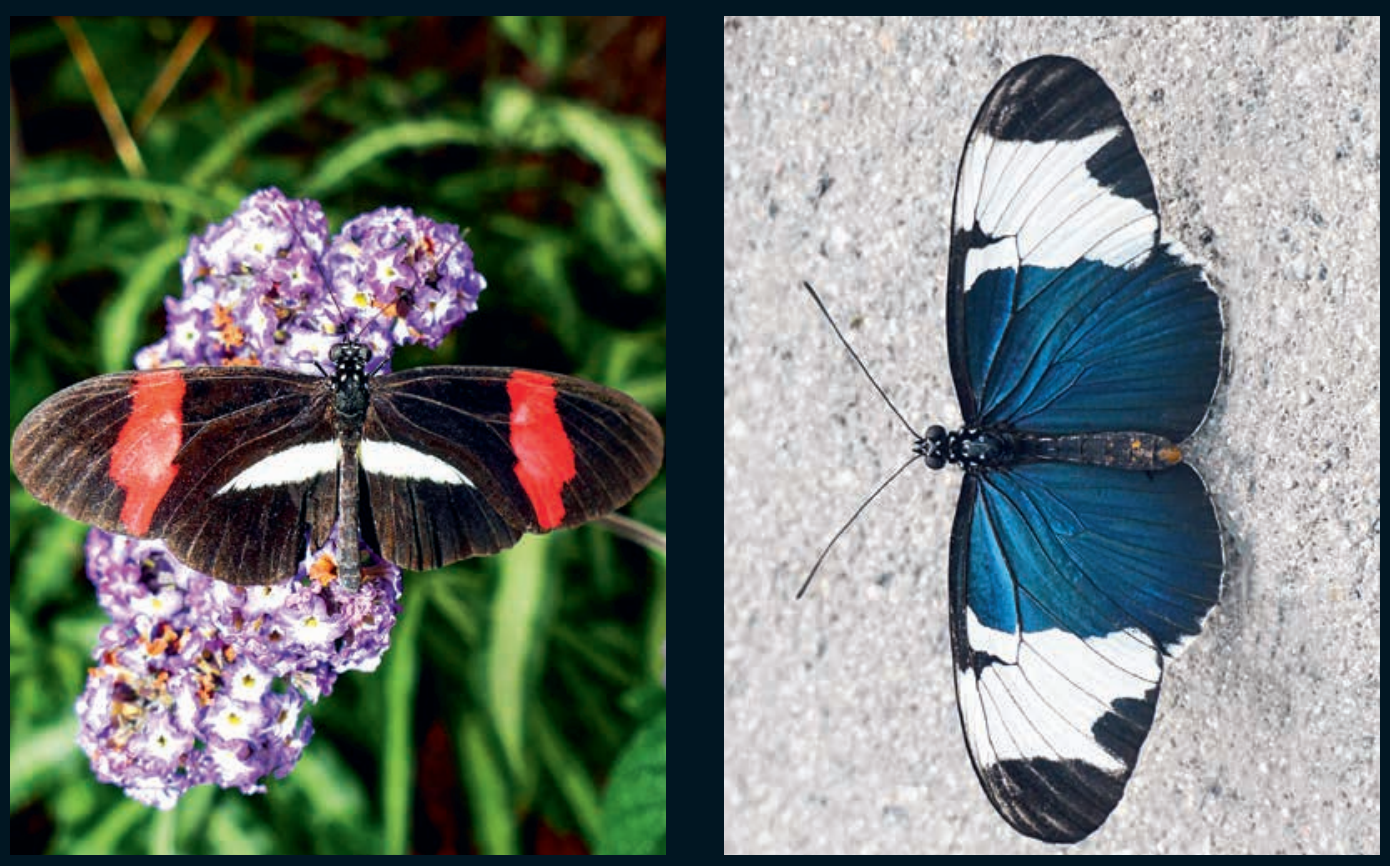

d

Abb. 16: Verschiedene Passionsblumenfalter. a: Goldener Passionsblumenfalter (Heliconius hecale); b: Tiger-Passionsblumenfalter (Heliconius ismenius); c: Postbote (Heliconius melpomene); d: Blauer Passionsblumenfalter (Heliconius sapho).

(Fotos: H. Steinecke) 

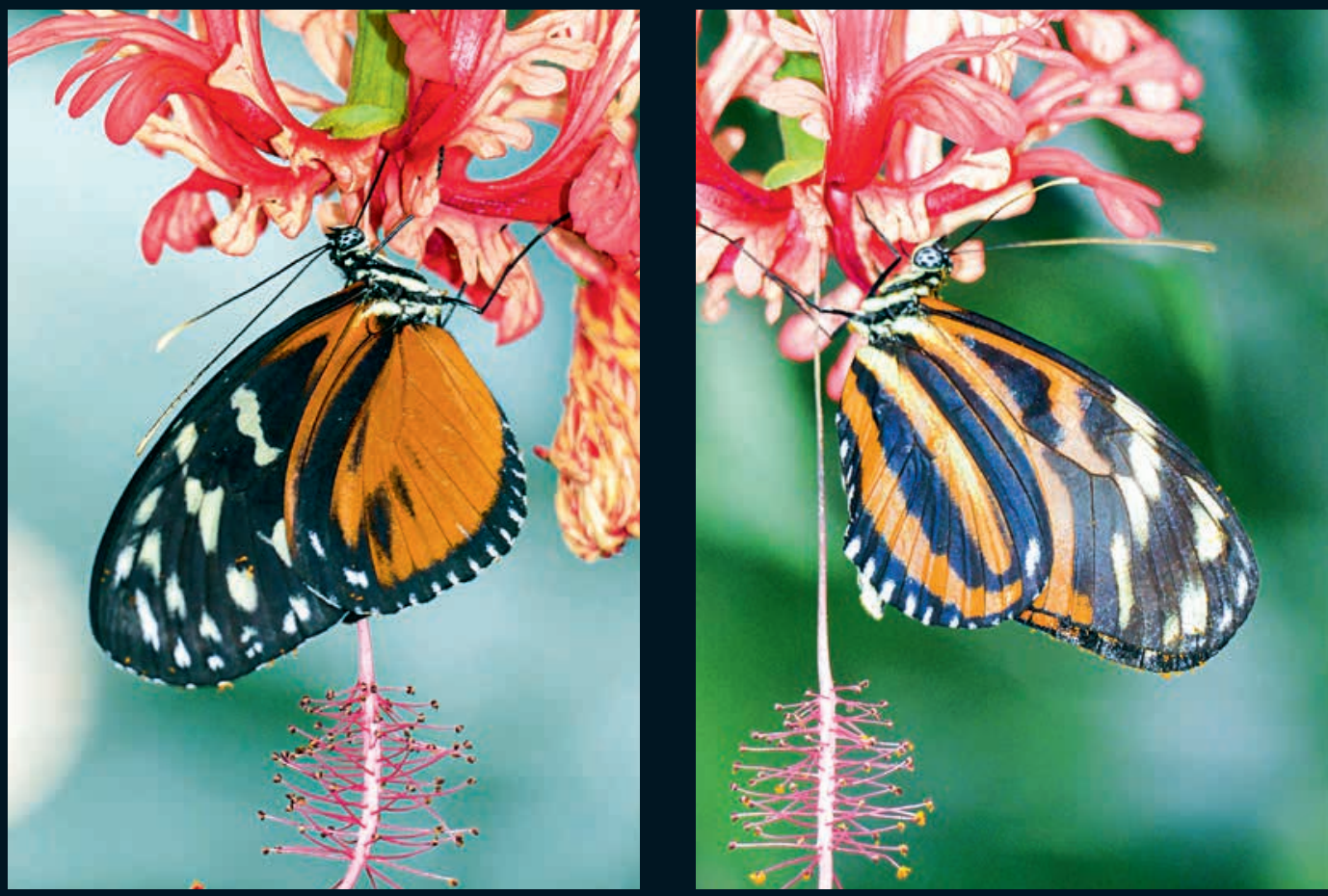

a

b
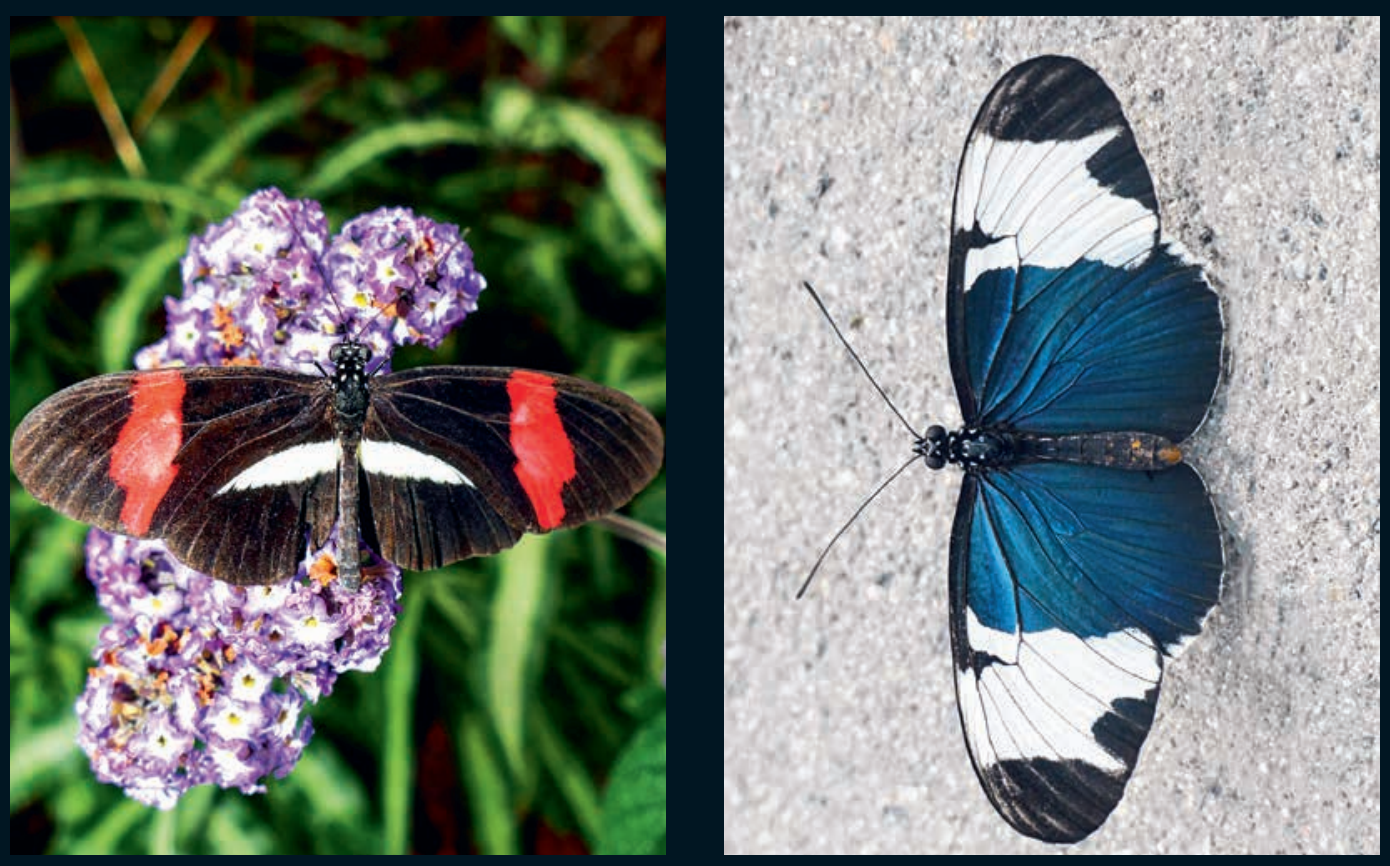

d

Abb. 16: Verschiedene Passionsblumenfalter. a: Goldener Passionsblumenfalter (Heliconius hecale); b: Tiger-Passionsblumenfalter (Heliconius ismenius); c: Postbote (Heliconius melpomene); d: Blauer Passionsblumenfalter (Heliconius sapho).

(Fotos: H. Steinecke) 

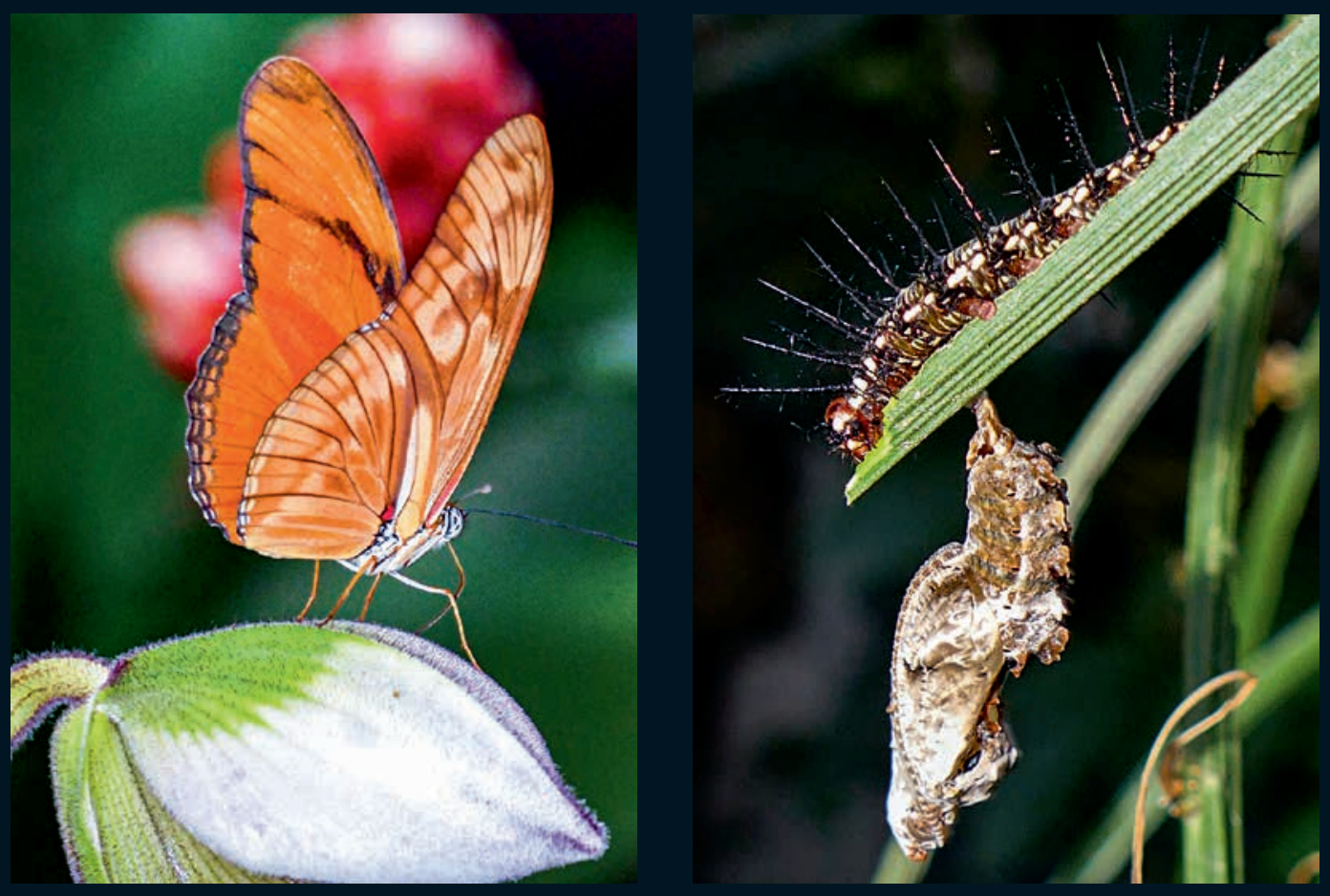

b
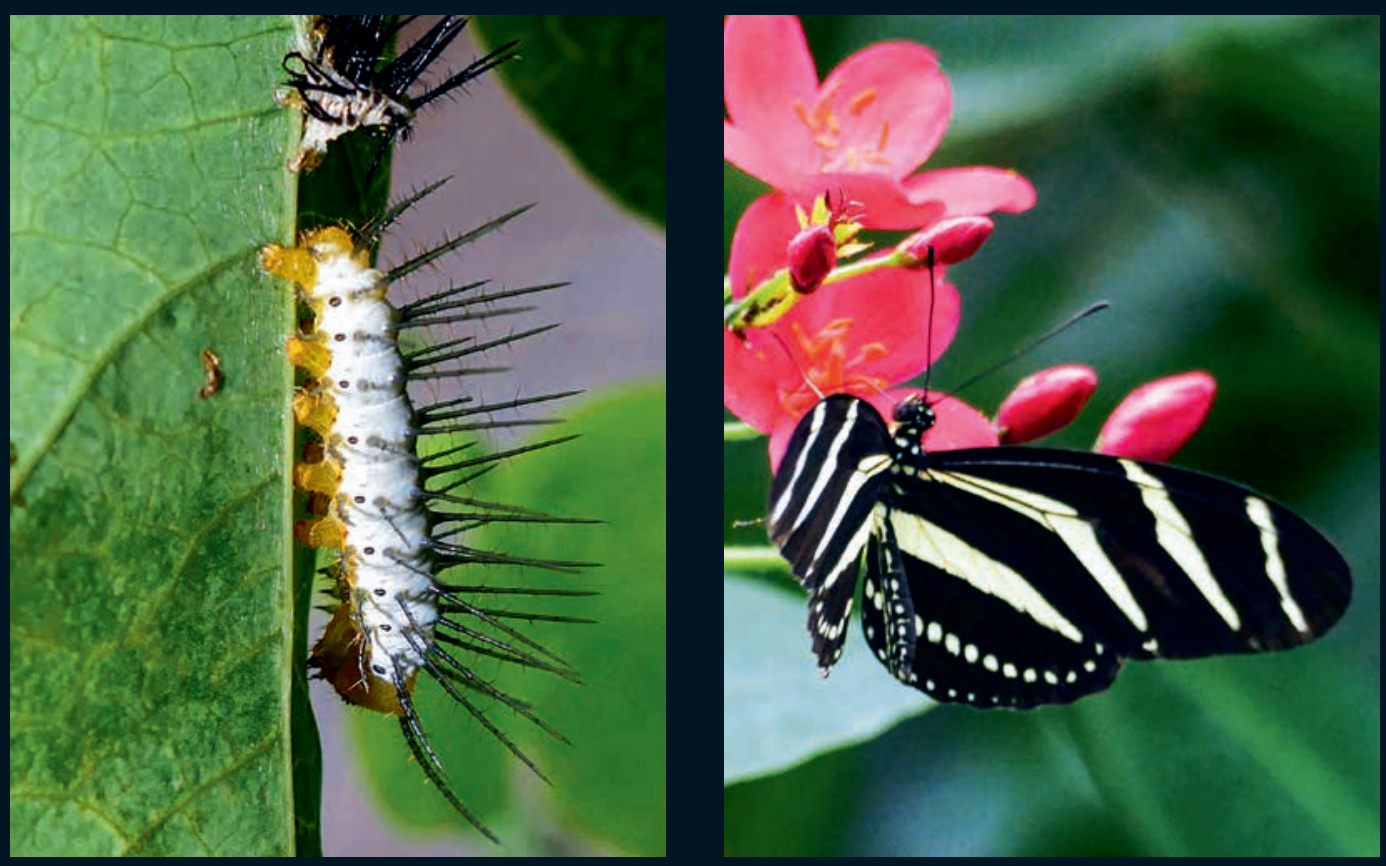

d

Abb. 17: Zwei Passionsblumenfalter, die sich bei uns auch vermehren, dazu ihre Raupen. a: Julia-Falter (Dryas iulia); b: Junge Raupe und Puppe des Julia-Falters; c: Frisch gehäutete Raupe des Zebrafalters (Heliconius charithonia); d: Zebrafalter an einer Jatropha-Blüte. (Fotos: H. STEINECKe) 
auffällig bunt gefärbt mit Farbkombinationen von schwarz, gelb, rot, orange, blau und weiß. Diese Warnfarben weisen auf die Giftigkeit und Ungenießbarkeit der Tiere hin. Die für die Schmetterlinge selbst nicht giftigen Glycoside nehmen sie als Raupe aus den Blättern ihrer Futterpflanzen (Passionsblumen, Passiflora) auf. Unter den vielen Passionsblumenfaltern gibt es oft ähnlich gefärbte Arten. Das ist ein klassisches Beispiel für Müller'sche Mimikry. Dies bedeutet, dass mehrere giftige Arten sehr ähnliche Warnfarbenmuster tragen, so dass Fraßfeinde artübergreifend dieses Muster vermeiden lernen. Zwei ähnlich gefärbte Heliconius-Arten in unserem Blüten- und Schmetterlingshaus sind Goldener Passionsblumenfalter (Heliconius hecale) und Tiger-Passionsblumenfalter ( $H$. ismenius). Der Schmetterling mit dem schönen Namen Konsul Fabius (Consul fabius) ist zwar auch ein Edelfalter, aber mit Passionsblumenfaltern nicht näher verwandt. Zusammengeklappt sieht er aus wie ein unscheinbares zerfranstes Blatt, auf der Flügeloberseite zeigt er eine ähnliche orange-schwarze Farbgebung und Musterung wie Passionsblumenfalter, womit er diese häufigen giftigen Falter imitiert.

Heliconius-Arten ernähren sich von Pollen (Eberhard et al. 2009). Oft ist zu sehen, dass ihre Flügel mit Pollen beladen sind, den sie möglicherweise beim Besuch einer weiteren Blüte auch auf der Narbe abstreifen. Die energiereiche eiweißhaltige Pollenkost verleiht den Schmetterlingen eine relativ lange mögliche Lebensdauer von einigen Wochen.

Markante Arten in unserem Haus sind auch der Zebrafalter (Heliconius charitonus) und der Juliafalter (Dryas iulia), letzterer wegen seiner leuchtend orangen Flügelfärbung auch Flamme genannt. Beide Arten legen regelmäßig Eier an Passionsblumen ab. Aus ihnen entwickeln sich bedornte Raupen, die Sturzpuppen ähneln welken Blättern. Einige Passionsblumen wiederum haben eine Strategie entwickelt, durch Punkte auf ihren Blättern Eier der Heliconiinae zu imitieren und diese so davon abzuhalten, auf vermeintlich bereits „besetzte“ Blätter Eier zu legen (siehe z. B. DÖRKEN \& JAGEL 2011).

\section{Ritter unter den Faltern}

$\mathrm{Zu}$ den Ritterfaltern (Papilionidae) gehören auch die Schwalbenschwänze (Papilio). Bei uns ist nur die einzige Art Papilio machaon heimisch. Die Gattung ist auf der Erde jedoch weit verbreitet mit einem Schwerpunkt in der Neuen Welt. Typisch sind ihre bogig ausgerandeten Flügel, und die oft, aber nicht bei allen Arten und nicht immer bei beiden Geschlechtern geschwänzten Hinterflügel. Häufig weisen sie eine schwarz-gelbe Musterung auf, wobei es auch andersfarbige wie neongrüne, blaue und rote Arten gibt. Der Königs-Schwalbenschwanz (Papilio thoas) mit einer stattlichen Flügelspannweite von $14 \mathrm{~cm}$ ist in den Tropen der Neuen Welt weit verbreitet. In manchen Regionen bildet er durchgehend neue Generationen. Dementsprechend ist er auch ein beliebter und oft in Schmetterlingshäusern gehaltener Falter. Die Schmetterlinge paaren sich auch in den Schmetterlingshäusern regelmäßig. Paarungswillige Männchen gruppieren sich oft, um den Weibchen zu imponieren. Männchen versuchen aber auch, sich gegenseitig aus einem Territorium zu vertreiben. Während der Paarung sind Männchen und Weibchen aneinander „angedockt“ und sitzen mehrere Minuten lang flach ausgebreitet auf Pflanzen oder auf dem Boden.

Raupenfutterpflanzen können ihnen relativ leicht angeboten werden, denn sie bevorzugen CitrusPflanzen und Pfeffergewächse. Der Ohren-Pfeffer (Piper auriculata) mit seinen großflächigen Blättern bietet sich als Futterpflanze an. Die Raupen von Papilio thoas sind sehenswert. Aus den gelben Eiern schlüpfen die kleinen Räupchen. Sie sind grau-grün marmoriert und gut getarnt. Außerdem tragen sie unregelmäßig weiße Flecken, so dass die Raupen an Vogelkot erinnern und von Fressfeinden verschmäht werden. Die ausgewachsenen Raupen werden etwa daumengroß. Bei Störung stülpen sie eine orangerote Nackengabel aus und verströmen einen Gestank. Hiermit werden vor allem Fliegen und parasitische Wespen abgeschreckt. Zur Verpuppung "gurten“ sich die Raupen an einem Zweig oder Stamm der Futterpflanze fest. Die graubraune Gürtelpuppe ist als Aststückchen getarnt. 

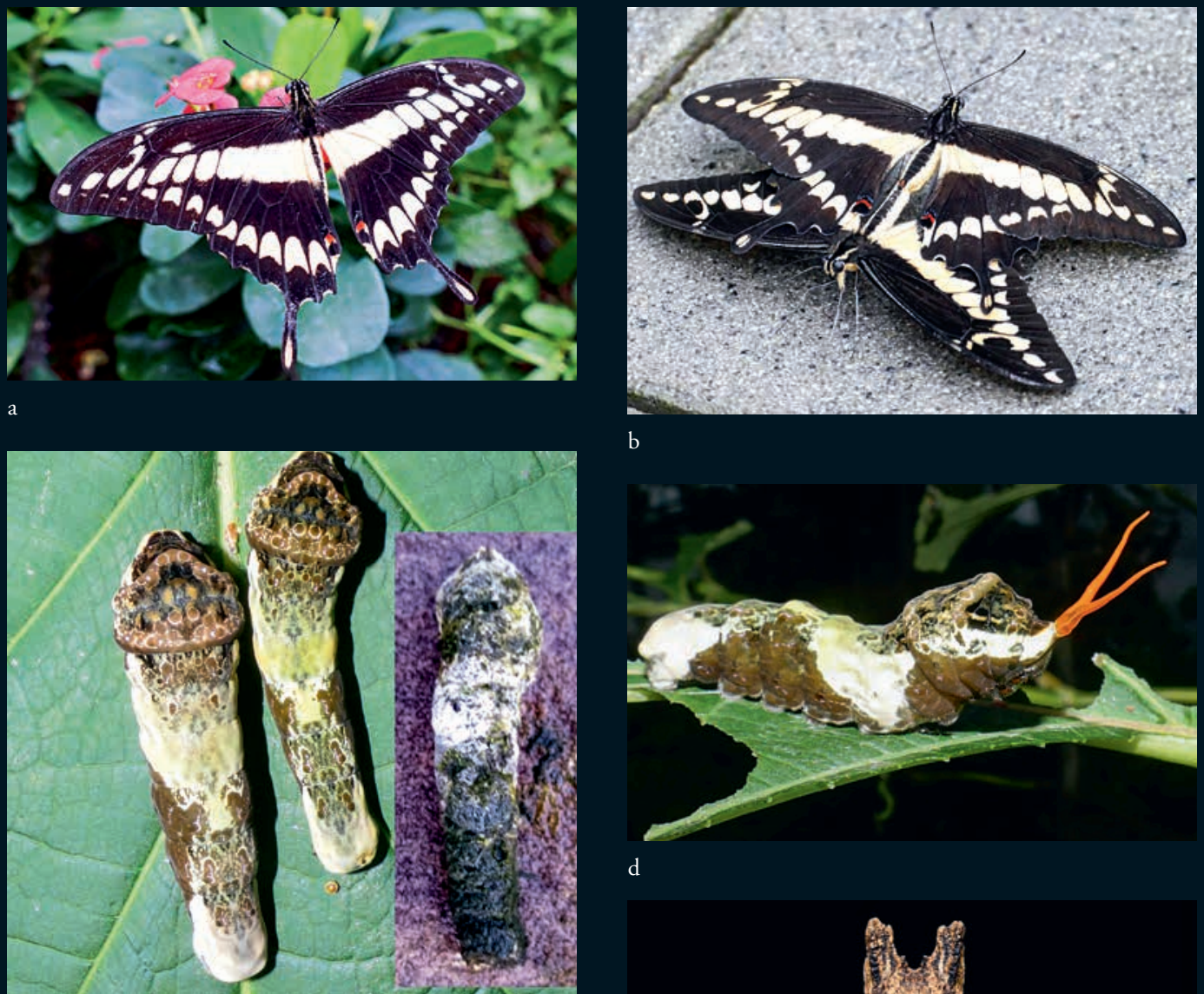

b
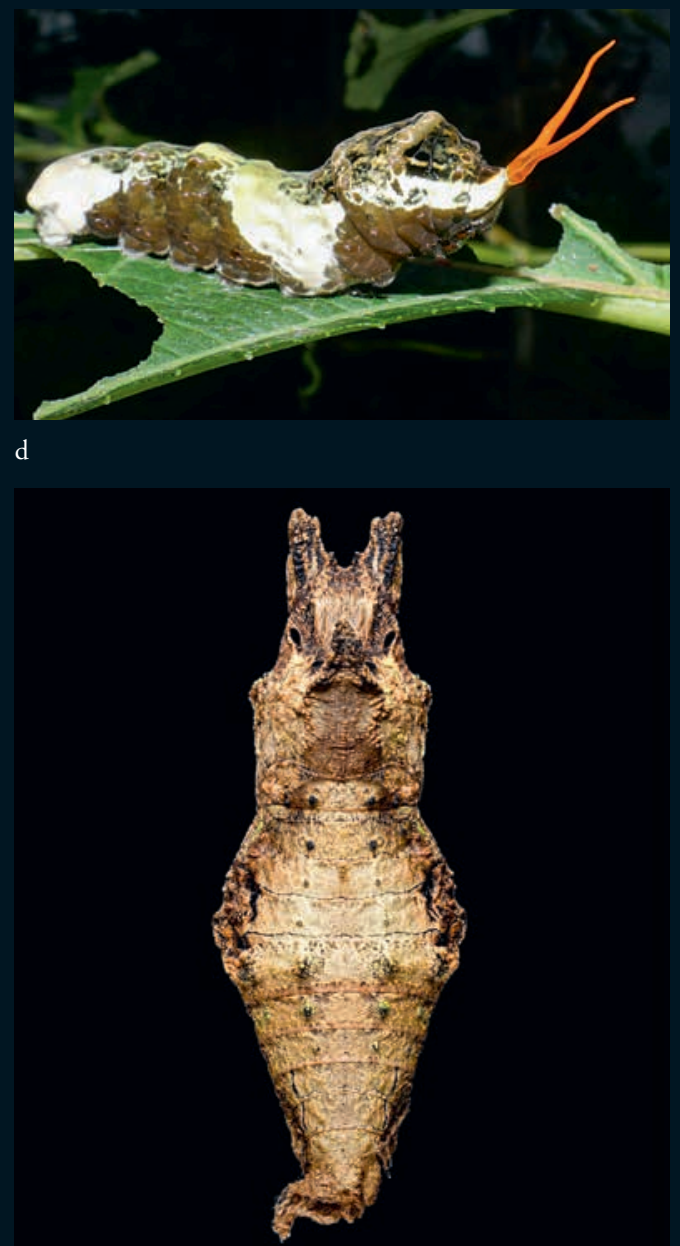

f

Abb 18: Königs-Schwalbenschwanz in verschiedenen Entwicklungsstadien. a: Königs-Schwalbenschwanz (Papilio thoas); b: Kopula; c: Die Raupen ähneln Vogelkot. Rechts im Bild Nilgans-Kot zum Vergleich. Unter der rechten Raupe ist ein gelbes Ei zu sehen; d: Raupe mit ausgestülpter Nackengabel; e: Vorpuppe; f: Puppe, gut getarnt als Aststückchen. (Fotos: J. MarkwIRTH, Puppe unten rechts; alle anderen: H. STeinecke) 



b

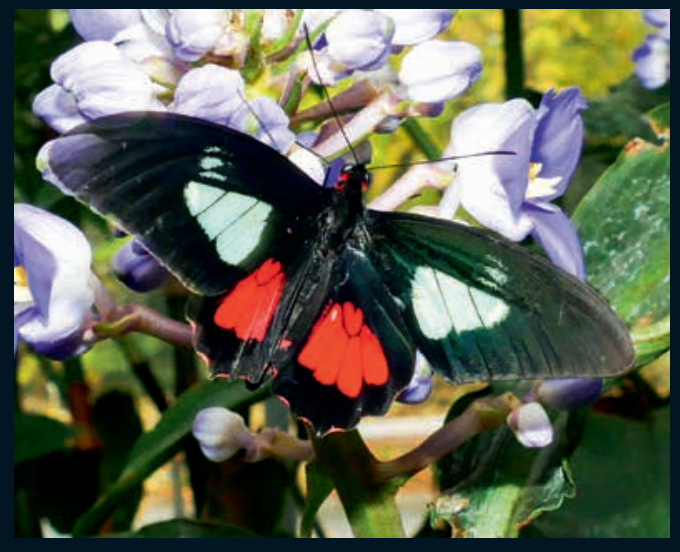

d
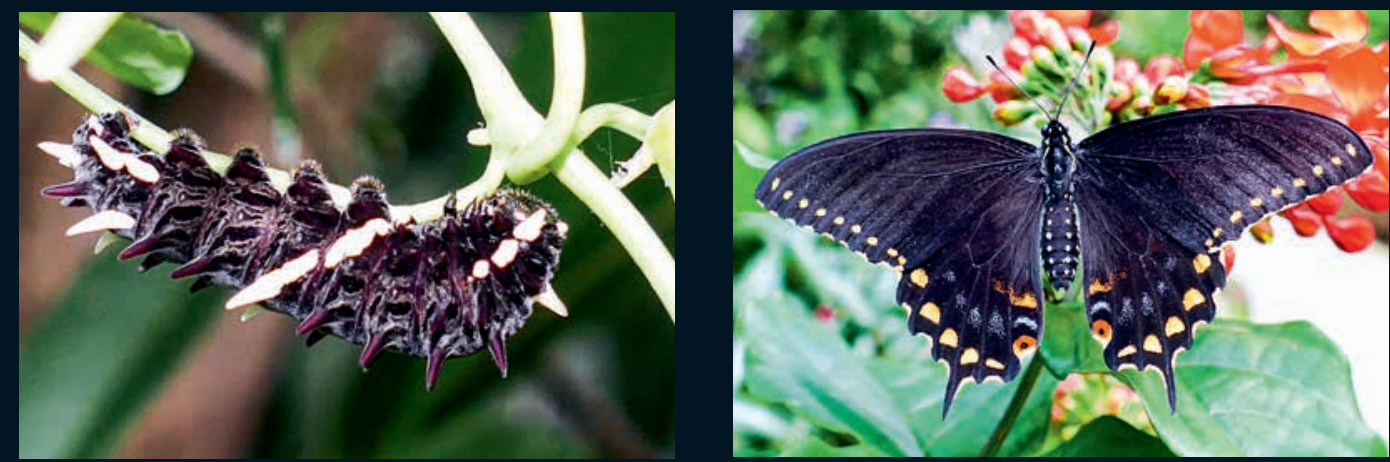

f

Abb. 19: Falter, Raupe und Puppe verschiedener Ritterfalter. a: Goldrandsegler (Battus polydamas); b: Blattähnliche Puppe des Goldrandseglers; c: Iphidamas-Rinderherz (Parides iphidamas); d: Parides iphidamas mit aufgeklappten Flügeln; e: Die Raupe von Parides iphidamas frisst Blätter von Aristolochia; f: Schwarzer Schwalbenschwanz, Weibchen (Papilio polyxenes).

(Fotos: H. STEINECKe) 
Mit $9 \mathrm{~cm}$ Spannweite deutlich kleiner ist der Schwarze Schwalbenschwanz (Papilio polyxenes). Dieser Schwalbenschwanz hat ein sehr weites Verbreitungsgebiet von Kanada bis Südamerika. Ein Weibchen kann im Alter von zwei bis vier Tagen über 400 Eier ablegen. Der GoldrandSegler (Battus polydamas) ist mit Schwalbenschwänzen eng verwandt. Seine Flügel sind ungeschwänzt. Die Flügeloberseiten des Weibchens sind größtenteils schwarz gefärbt mit einem randlichen weißlichgelben Band. Die Männchen haben größere Gelbanteile. Die Unterseite zeigt eine rote Musterung. Ebenfalls verwandt mit den Schwalbenschwänzen ist Parides iphidamas. Im Englischen wird die Art auch als „cattleheart" (Vieh- oder Rinderherz) bezeichnet. Der Schmetterling ist schwarz-rot-türkis gemustert. Die schwarzpurpur gefärbten Raupen mit weißen und dunklen dornigen Auswüchsen fressen die Blätter von Aristolochia. Auch sie waren schon mal in unserem Blüten- und Schmetterlingshaus anzutreffen.

\section{Ein echter Nachtfalter}

Rothschildia lebeau ist einer von mehreren Dutzend Arten dieser Gattung aus der Familie der Pfauenspinner (Saturniidae). Sie kommen vom südlichen Nordamerika bis Südamerika vor. Die meisten Arten sehen sich sehr ähnlich. Sie erinnern an den asiatisch verbreiteten, mit ihnen verwandten Atlasfalter (Attacus atlas), der wegen seiner Flügelspannweiten von $30 \mathrm{~cm}$ ziemlich bekannt ist. Rothschildia wird nur etwa halb so groß. Charakteristisch sind die vier fensterartigen, trüb durchsichtigen Flecken auf den Flügeln. Die Vorderflügel sind in eine gebogene Spitze ausgezogen, die je nach Art mal mehr oder weniger an einen Schlangenkopf erinnert. Die fingergroßen Raupen verpuppen sich in einem gespinstartigen Kokon. Von manchen Arten wurde aus den Kokons Seide gesponnen. Die Schmetterlinge leben nur wenige Tage. Die Weibchen lassen sich gut getarnt mit ausgebreiteten Flügeln an qut geschützten Standorten nieder. Sie haben verkümmerte Mundwerkzeuge und nehmen keine Nahrung auf. Sie warten auf die nachtaktiven Männchen. Nach der Begattung besteht ihre Aufgabe nur noch darin, Eier abzulegen, bald danach sterben sie.

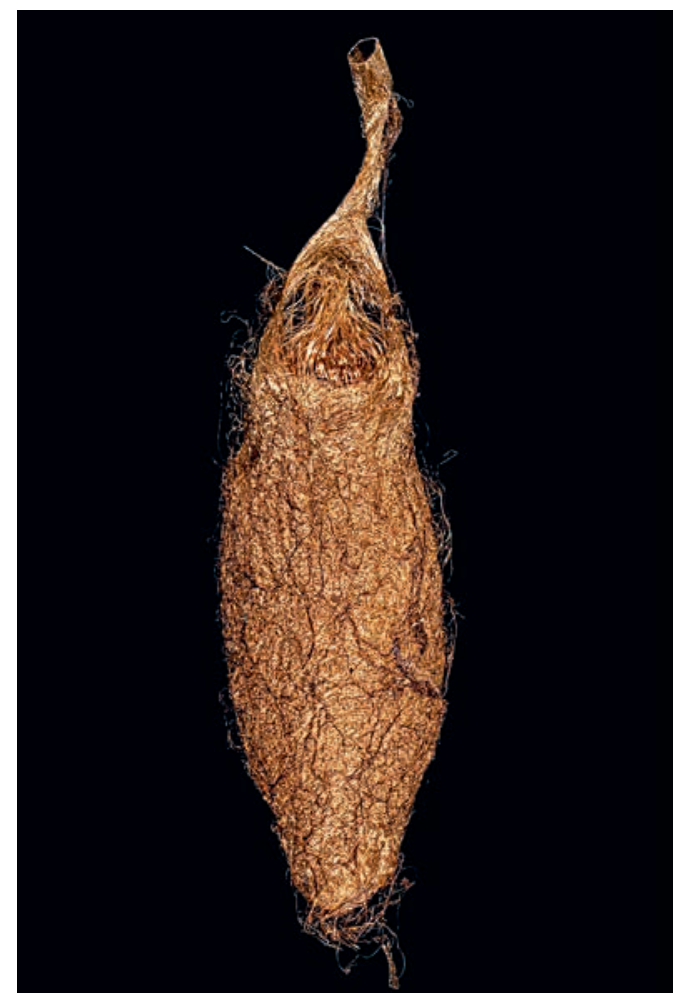

Abb. 20: Kokon von Rothschildia lebeau, im Inneren befindet sich die Puppe. (Foto: J. Markwirth)

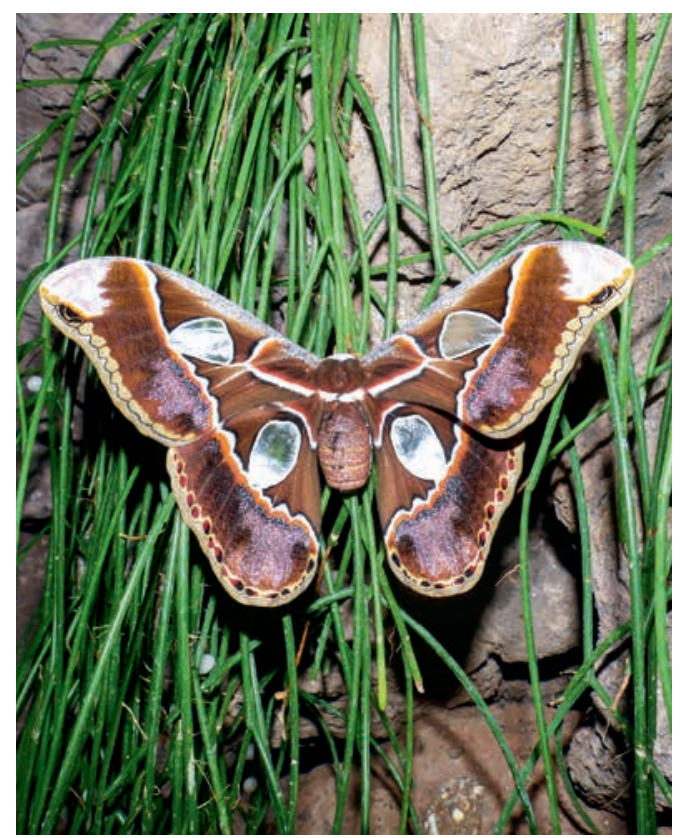

Abb. 21: Pfauenspinner (Rothschildia lebeau).

(Foto: H. Steinecke) 

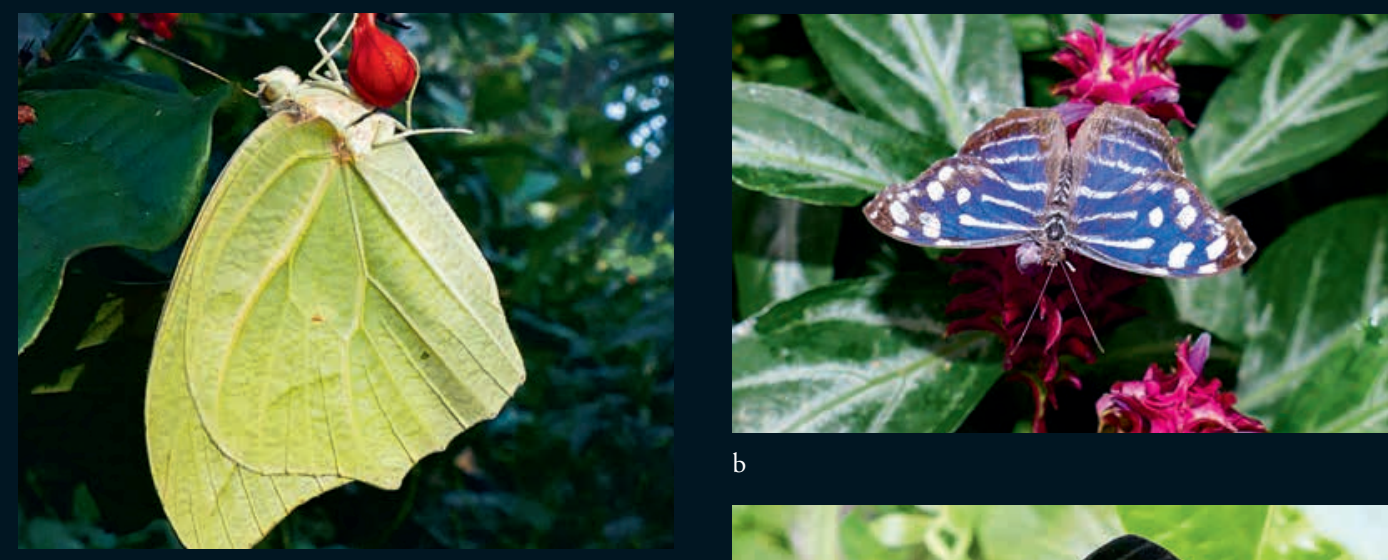

b
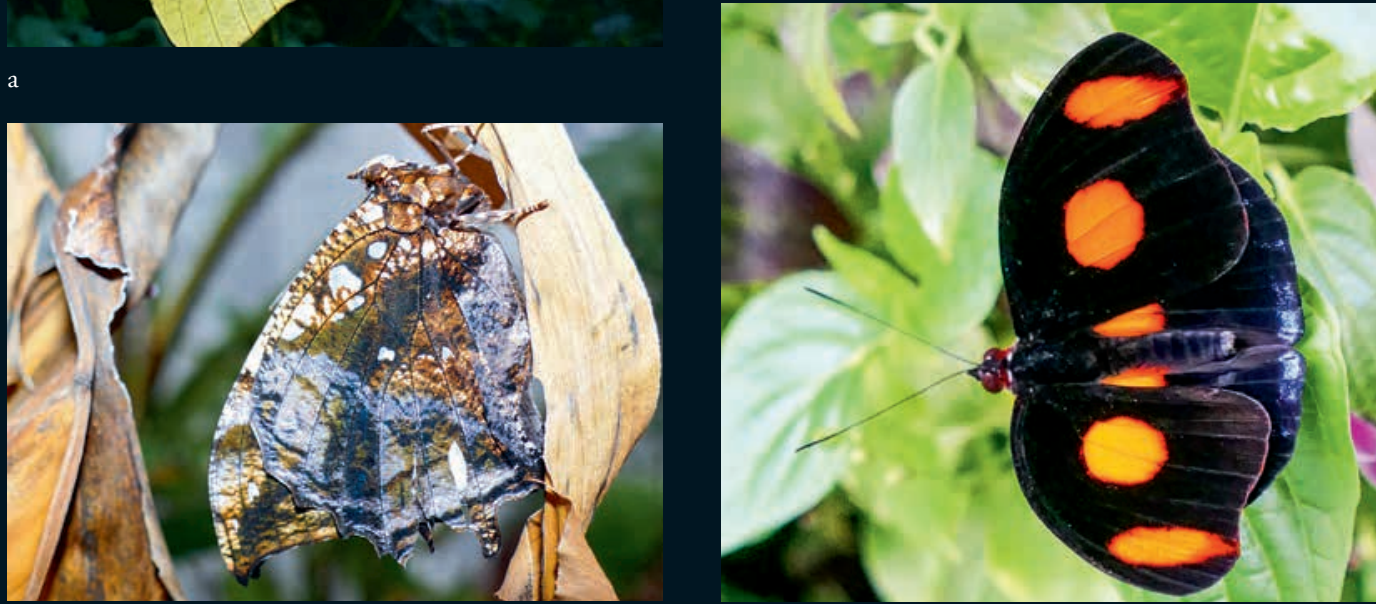

d
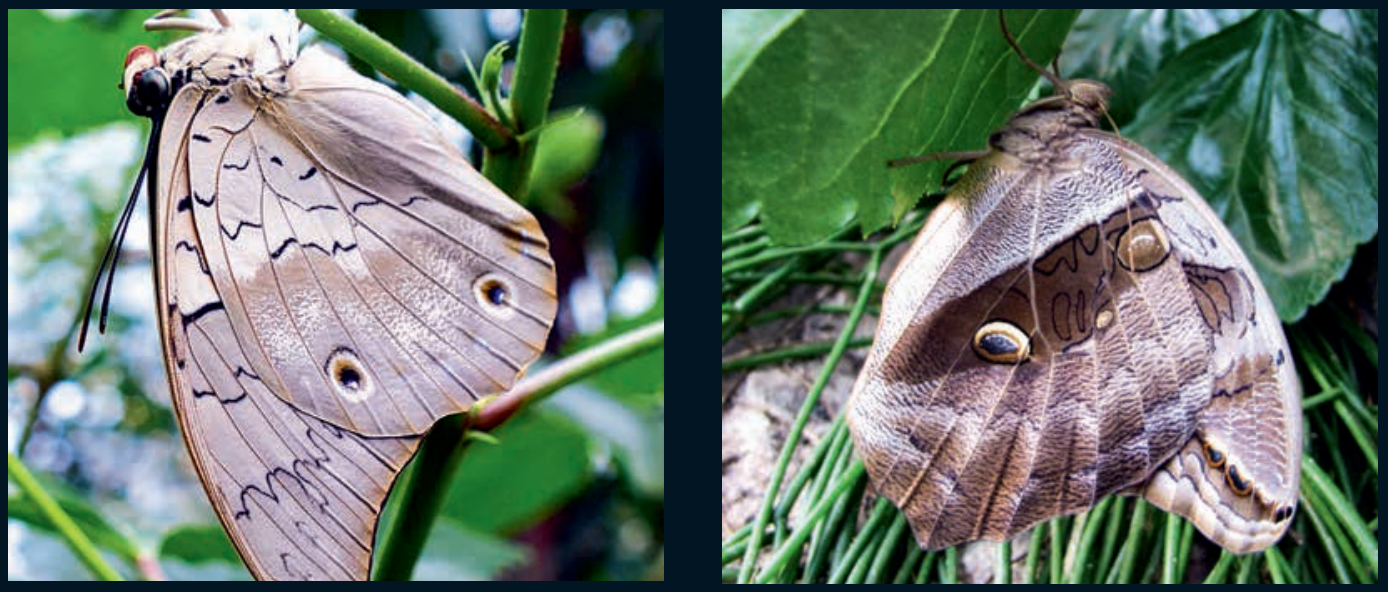

f

Abb. 22: Auswahl an Faltern, die nicht weiter im Text erwähnt sind, dennoch auch bei uns zumindest zeitweise fliegen. a: Weißer Schwefel (Anteos clorinde), Pieridae, Weißlinge; b: Blaue Welle, (Myscelia cyaniris), Nymphalidae, Edelfalter; c: Klytemnästra (Hypna clytemnestra), Nymphalidae, Edelfalter: wie ein welkes Blatt zwischen anderen welken Blättern; d: Feinschmecker (Catonephele numilia), Männchen, Nymphalidae, Edelfalter; e: Prepona laertes, Nymphalidae, Edelfalter: zusammengeklappt grau und unscheinbar, aufgeklappt schimmert er stahlblau; f: Eule (Eryphanis automedon), Nymphalidae, Edelfalter. (Fotos: H. STEINECKe) 


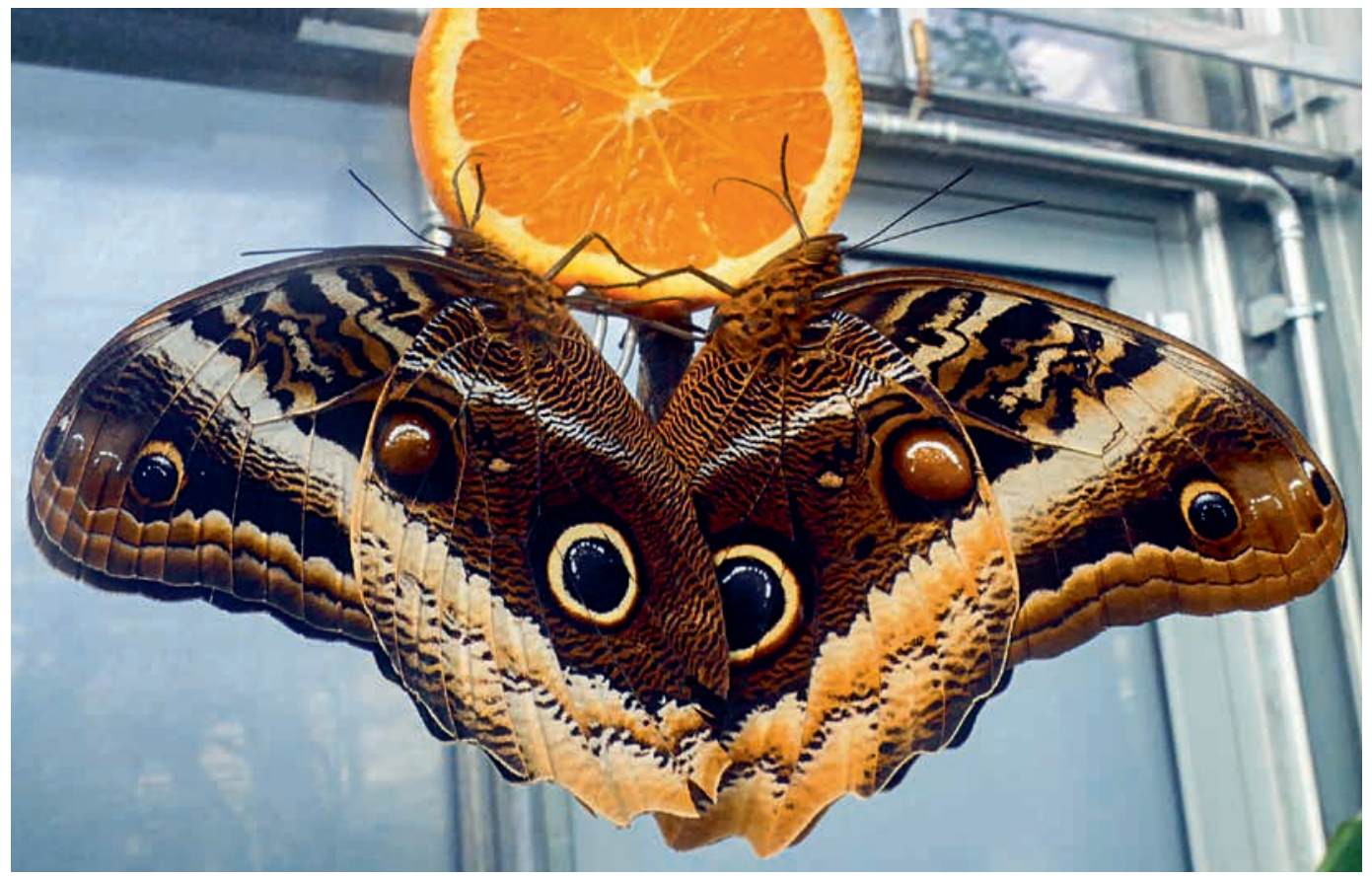

Abb. 23: Zwei Blaue Bananenfalter an einer Obstkette wirken wie ein einziger riesiger Schmetterling. (Foto: H. STEINECKE)

Unter den Pfauenspinnern gibt es viele Arten mit großen Faltern, aber auch großen Raupen, von denen einige Arten in großem Stil gesammelt und gegessen werden, so etwa die „Mopane worms“ (Gonimbrasia belina) im südlichen und „Chitoumou" (Cirina butyrospermi) im westlichen Afrika.

Je nach Saison verändert sich die Artzusammensetzung der gelieferten Puppen, so dass immer mal wieder andere Arten zu sehen sind. Die Kombination aus frei fliegenden Schmetterlingen und der im Nebenraum gezeigten Dauerausstellung zu Insekten und Blütenbiologie bietet viele Möglichkeiten, in das große Thema Insekten und ihre Beziehungen zu Pflanzen einzutauchen.

\section{Dank}

Großer Dank gilt Maria Gerlinde Blaese (Biologin im Garten der Schmetterlinge Schloss Sayn der Fürstin SAYN-WitTGenstein) für Beratung, kritische Durchsicht des Manuskriptes und Bereitstellung von Fotos. Dank gilt ebenso Jennifer MarkWIRTH (Frankfurt, https://flora-obscura.de/) für die Überlassung der Fotos von Puppen und Eiern.

\section{Literatur}

Dörken, V.M. \& Jagel, A. (2011): Passionsblumen - Der Palmengarten. 75: 114-121. https://doi.org/10.21248/palmengarten. 125 .

\section{Internetseite}

Eberhard et al. (2011):

https://homepage.univie.ac.at/harald.krenn/PDF/Eberhard\%20et\%20al.\%202009\%20Nectar\%20or\%20saliva. pdf.

\section{Anschrift der Autorinnen und Autoren}

Hilke Steinecke, Marco Schmidt, Alexander Becker, Justine Hillenbrand \& Beate Vaupel, Palmengarten Frankfurt, Siesmayerstraße 61, 60323 Frankfurt am Main, E-Mail: hilke.steinecke@stadt-frankfurt.de, marco.schmidt@stadt-frankfurt.de, alexander.becker@stadt-frankfurt.de, justine.hillenbrand@stadt-frankfurt.de, beate.vaupel@stadt-frankfurt.de ORCID-Nummern:

Hilke Steinecke: https://orcid.org/0000-0002-4618-4867 Marco Schmidt: https://orcid.org/0000-0001-6087-6117 